\title{
Cellular and Molecular Mechanisms of Sexual Differentiation in the Mammalian Nervous System
}

\author{
Nancy G. Forger*, J. Alex Strahan, and Alexandra Castillo-Ruiz \\ Neuroscience Institute, Georgia State University, Atlanta GA 30303, United States
}

E-mail addresses:

nforger@gsu.edu (N.G. Forger)

acastilloruiz@gsu.edu (A. Castillo-Ruiz)

jstrahan1@student.gsu.edu (J.A. Strahan)

${ }^{*}$ Corresponding author

Nancy G. Forger

Neuroscience Institute

Georgia State University

P.O. Box 5030

Atlanta, GA 30303, USA

Tel: +1 4044135888

Fax: + 14044135446

E-mail: nforger@gsu.edu 


\section{Abstract}

Neuroscientists are likely to discover new sex differences in the coming years, spurred by the National Institutes of Health initiative to include both sexes in preclinical studies. This review summarizes the current state of knowledge of the cellular and molecular mechanisms underlying sex differences in the mammalian nervous system, based primarily on work in rodents. Cellular mechanisms examined include neurogenesis, migration, the differentiation of neurochemical and morphological cell phenotype, and cell death. At the molecular level we discuss evolving roles for epigenetics, sex chromosome complement, the immune system, and newly identified cell signaling pathways. We review recent findings on the role of the environment, as well as genome-wide studies with some surprising results, causing us to rethink often-used models of sexual differentiation. We end by pointing to future directions, including an increased awareness of the important contributions of tissues outside of the nervous system to sexual differentiation of the brain.

Keywords: brain; cell death; epigenetic; glia; immune system; maternal care; microbiota; NIH; sex difference; stress 


\section{Introduction}

The National Institutes of Health $(\mathrm{NIH})$ in the U.S.A. recently announced that grant proposals submitted after January, 2016 must include sex or gender in study designs, or explain why not (NIH Notice Number: NOT-OD-15-102). When sex differences are looked for, they are often found, so we are likely to be on the cusp of learning about a host of new sex and gender differences in the brain. Unraveling the underlying mechanisms will become a priority, and this is an opportune time to examine what research to date has taught us about how neural sex differences develop and change cellular function.

The NIH initiative came in response to observations that a disproportionate number of pre-clinical studies have for many years used only male subjects or cultured cells of unknown sex (Beery and Zucker, 2011; Blanchard et al., 1995; Sechzer et al., 1994). Over 70\% of the basic research articles published in key neuroscience journals in a recent year used only males or did not specify the sex of subjects (Beery and Zucker, 2011), despite overwhelming evidence that there are important differences between male and female brains. Although the most prominent sex differences are often seen for reproductive functions, differences in other realms, such as cognition, energy balance, and stress responsiveness, are also well established (Bangasser and Valentino, 2012; Imwalle et al., 2006; Kimura, 2002; Mauvais-Jarvis, 2015). Moreover, the effects of some manipulations don't just differ by sex, but may push the brain and behavior in opposite directions in males and females (e.g., Oomen et al., 2009; Shors et al., 2001; Veenema et al., 2013; Waddell et al., 2008).

Several previous reviews on sexual differentiation of the mammalian brain and behavior are available (e.g.,Forger et al., 2015; McCarthy et al., 2009). Here, we focus on neural sex differences for which the cellular or molecular mechanisms underlying the difference are known. By necessity, most of the evidence we present comes from work on rats or mice, since rodent species have been most amenable to studies at the cell and molecular level; when possible, we indicate where results apply more broadly. We attempt to present enough of the 
older and background material for those who may be new to the field, and also emphasize the most recent findings or those that illustrate a novel mechanism.

\subsection{Agents of Sexual Differentiation}

Broadly speaking, sex differences can be attributed to three interacting factors: sex chromosomes, gonadal hormones, and the environment. Although some neural sex differences develop under the direct influence of genes on the sex chromosomes (see Section 3 below), in most cases, effects of the sex chromosomes appear to be indirect, and mediated by hormones produced by the gonads. Only males inherit a $Y$ chromosome from the father, and the sexdetermining region of the $Y(S r y)$ gene, in cooperation with downstream genes, induces the initially "bipotential" embryonic gonads to develop into testes (Kashimada and Koopman, 2010; Koopman et al., 1991). The fetal testes begin secreting testosterone within days after they differentiate (approximately embryonic day (E) 14 in the mouse, E16 in the rat, and week 10 of gestation in humans) and a wealth of data indicates that this hormone, or a metabolite, is responsible for masculinization of the brain as well as the periphery (Forger et al., 2015; McCarthy, 2011).

Testosterone can act via the androgen receptor, or may be converted (aromatized) to an estrogen at target cells by the cytochrome P450 aromatase enzyme, and subsequently act via estrogen receptors (Naftolin, 1994; Roselli et al., 2009). Conversion of testosterone to estradiol is required for full masculinization of many brain features in rodents (but see Zuloaga et al., 2008), whereas androgens are thought to play the dominant role in sexual differentiation of the brain in primates (Thornton et al., 2009; Wallen, 2005).

Effects of gonadal steroid hormones have traditionally been characterized as either "organizational" or "activational" (Phoenix et al., 1959). Organizational, or programming, effects outlast the hormone exposure: e.g., when hormone exposure early in life induces an enduring, or permanent change. Activational, or acute, effects are defined as those requiring the 
continued presence of the hormone. In many cases, both programming and acute actions of steroids are required. In the classic experiments by Phoenix, Goy, Gerall and Young (1959), for example, the exposure of female guinea pigs to testosterone in utero permanently decreased female sexual behavior and increased male sexual behavior in adulthood, but this could only be seen when sex-specific copulatory behaviors were "activated" by treatment with the appropriate steroids in adulthood. Over 50 years later, most research in the field has shifted to rats and mice, and substantial progress has been made in understanding neuroanatomical and neurochemical changes that correlate with the differentiation of behavior, as well as the cellular and molecular mechanisms that may underlie these effects.

\subsection{New(er) Approaches to Old Questions}

One puzzle presented itself early on in studies of sexual differentiation of the rodent brain: since steroids in maternal circulation can reach the fetus, why aren't all fetuses masculinized by maternal estrogens? The proposed solution was that alpha fetoprotein (AFP), an estrogen-binding protein that is highly abundant in fetal plasma, sequesters peripheral estrogens and keeps them from reaching the brain (McEwen et al., 1975). Other evidence, however, suggested that AFP might instead be a carrier protein delivering estrogens to the brain (Toran-Allerand, 1984). This issue was recently reexamined by studying the brain and behavior of Afp knockout mice. For most traits, female Afp -/ mice are convincingly male-like (Figure 1; Bakker et al., 2006; Gonzalez-Martinez et al., 2008), supporting the idea that AFP normally protects female fetuses from circulating estrogens. There are some interesting exceptions, however: odor preferences and vasopressin immunoreactivity in the brain remain female-typical in female Afp knockouts (Bakker et al., 2006; Bakker et al., 2007), suggesting that exposure to estrogens during embryonic development is not sufficient to masculinize these traits in mice. Although AFP is present in the plasma of fetal primates, including humans, it does not avidly bind estrogens (Aussel and Masseyeff, 1983), so is unlikely to protect the fetal brain from 
estrogen exposure. Other steroid binding proteins may play that role, or no such protection may be needed, if sexual differentiation of the brain and behavior in primates is primarily mediated by androgens (Thornton et al., 2009; Wallen, 2005).

A second question concerns the relationship between levels of gonadal steroids in the blood and those in the brain. Testosterone secretion begins soon after testis differentiation, and a second surge occurs at birth (Resko, 1985; Reyes et al., 1974; Weisz and Ward, 1980). Brain levels of androgens and estrogens may not simply reflect plasma levels, however. A recent radioimmunoassay study found that neural levels of androgens and estrogens vary by age and brain region in complex patterns that do not correlate with peripheral hormone levels and cannot be explained simply by known levels of aromatase (Konkle and McCarthy, 2011). Even more surprising, combined gonadectomy and adrenalectomy of rats on the day of birth did not alter brain levels of estrogens or androgens three days later (Konkle and McCarthy, 2011). The answer to this puzzle may lie in the brain itself being capable of steroid synthesis de novo (Robel and Baulieu, 1995). Many new roles for neurosteroid production have been discovered in the last decade (Krentzel and Remage-Healey, 2015; Micevych and Sinchak, 2011), but mainstream theories of sexual differentiation of the brain have not yet incorporated this concept, which makes this an area ripe for investigation.

\section{Cellular Bases of Sex Differences}

While prenatal testosterone exposure differentiates the periphery, the neonatal testosterone surge is most closely linked to sexual differentiation of the brain and behavior in rodents. In principle, gonadal steroids could cause sex differences by altering any of the major neurodevelopmental events: neurogenesis, migration, differentiation of phenotype, or cell death (reviewed in Forger, 2006, 2009). However, the majority of neurogenesis and cell migration is complete prior to birth (i.e., before the neonatal testosterone surge), which makes it less likely that hormones act on these processes to differentiate the brain. 
An exception is that many hippocampal neurons are generated postnatally, and newborn male rats have a two-fold higher rate of cell birth in the hippocampus than do females (Zhang et al., 2008). The rate of hippocampal cell genesis in females can be increased to male levels by neonatal treatment with either testosterone or estradiol and, in the CA1 region, many of the newborn cells differentiate into neurons (Bowers et al., 2010). Sex differences in the size of the hippocampus in adults are subtle, however, so the sex difference in the production of new cells may be offset by differences in cell loss at some point in development.

Evidence of a role for migration in sexual differentiation of the brain comes from studies using live-cell fluorescent video microscopy to study cell movements in slice cultures of the embryonic brain (Henderson et al., 1999; Knoll et al., 2007). For example, neurons in the preoptic area/anterior hypothalamus (POA/AH) of E14 female mice move faster and more frequently than those in males (Knoll et al., 2007). Administration of estradiol decreases the rate of movement of dorsal POA/AH cells while increasing the movement of cells located more ventrally (Knoll et al., 2007). There is also a sex difference in the location of neurons expressing estrogen receptor $\beta(E R \beta)$ in the anteroventral periventricular nucleus (AVPV) of the hypothalamus of rats, with these cells located more medially in females than in males (Orikasa et al., 2002). This sex difference is reversed by gonadectomy of males and treatment of females with estradiol at birth (Orikasa et al., 2002), confirming its dependence on neonatal gonadal steroid exposure.

This last example raises an interesting conundrum, however. The sex difference in cell position of ERß cells could be due to a difference in cell migration. But such a sex difference could also be due to cell death (Section 2.1) or the differentiation of phenotype (Section 2.3) if, for example, laterally located cells preferentially die in females or are induced to express ER $\beta$ in males. Distinguishing between these possibilities is not straightforward, and as yet there is no sex difference in the adult brain that has been definitively linked to differential cell migration. 


\subsection{The Role of Cell Death}

Neural development in all vertebrates is accompanied by widespread cell death. In mammals, many neurons are eliminated within hours of their birth, while still within proliferative zones near the ventricles (Blaschke et al., 1998; Kuan et al., 2000), and a second wave, known as "postmitotic cell death," eliminates about $50 \%$ of the neurons that have migrated and begun to make axonal connections (Kuan et al., 2000; Oppenheim, 1985). Postmitotic cell death is controlled by members of the Bcl-2 family of proteins, and its timing overlaps with the critical period for sexual differentiation in rodents (Ahern et al., 2013; Roth and D'Sa, 2001). In contrast to the limited evidence for neurogenesis or migration, a number of studies support a role for the hormonal control of cell death in the development of neural sex differences.

In several of the best-studied neural sex differences, males have more neurons than females; these include the spinal nucleus of the bulbocavernosus (SNB), principal nucleus of the bed nucleus of the stria terminalis (BNSTp), and sexually dimorphic nucleus of the preoptic area of the hypothalamus (SDN-POA). Although best studied in rats and mice, each of these cell groups has homologous nuclei (with similar male-biased sex differences) in other mammals, including humans (Allen and Gorski, 1990; Byne et al., 2000; Forger, 2009; Forger and Breedlove, 1986, and for a species that presents exceptions, see Holmes et al., 2009).

Pre- or neonatally, rats and mice of both sexes have similar numbers of cells in the SNB, BNSTp, and SDN-POA, but females have more dying cells than males either around the time of birth (SNB) or at the end of the first postnatal week (BNSTp and SDN-POA) (Ahern et al., 2013; Chung et al., 2000; Davis et al., 1996; Gotsiridze et al., 2007; Kato et al., 2012; Nordeen et al., 1985; Wu et al., 2009). In mice in which the pro-survival protein Bcl-2 is overexpressed, or in which the pro-death gene Bax is eliminated, sex differences in the SNB and BNSTp are reduced or eliminated (Figure 2; Forger et al., 2004; Jacob et al., 2005; Zup et al., 2003). Neonatal female rats also have reduced $\mathrm{Bcl}-2$ and increased Bax expression in the SDN-POA compared 
to males, and estradiol treatment of females on postnatal day 5 prevents these differences in expression (Tsukahara et al., 2008; Tsukahara et al., 2006).

Sex differences in the SNB, BNSTp and SDN-POA can be eliminated by treating female rats or mice with testosterone around the time of birth, with androgenic metabolites of testosterone required for masculinization of the SNB (Breedlove and Arnold, 1981; Sengelaub and Forger, 2008), and estrogenic metabolites for the BNSTp and SDN-POA (Arai et al., 1996; Chung et al., 2000; Hisasue et al., 2010). Thus, the hormonal suppression of cell death by either androgenic or estrogenic metabolites of testosterone underlies masculinization of total cell number in the SNB, BNSTp and SDN-POA.

\subsubsection{Site of Hormone Action}

Although testosterone and its metabolites control the number of cells in the SNB, BNSTp, and SDN-POA, it may not act directly on those cell groups to do so. For example, SNB cells do not express high levels of androgen receptors until after the perinatal period when the hormone controls their survival (Jordan et al., 1991), and androgens can rescue SNB cells that themselves never express functional androgen receptors (Freeman et al., 1996). SNB motoneurons innervate striated muscles associated with the phallus, and these muscles express androgen receptors perinatally (Fishman et al., 1990; Jordan et al., 1997). This, and other evidence (e.g., Fishman and Breedlove, 1992), led to the suggestion that androgens act at the muscles, with trophic factors from the muscles promoting SNB cell survival (Forger et al., 1993; Forger et al., 1995).

Muscles are comprised of multiple cell types, however, including myocytes (muscle fiber cells), satellite cells, and fibroblasts. To test whether androgen action at myocytes could solely explain effects on SNB cell survival, Niel and colleagues generated rats expressing functional androgen receptors only in myocytes, and inactive, mutant receptors in all other cells throughout the body (Niel et al., 2008). SNB motoneuron number and target muscle size was female-like in 
these animals, even after perinatal exposure to androgens (Figure 3; Niel et al., 2008). This suggests that androgen action at muscle fibers alone is not sufficient for rescue of the SNB neuromuscular system. Other cells within muscle tissue may be important (e.g., satellite cells, Swift-Gallant and Monks, 2013), or androgens may act at multiple sites within and outside of muscle.

It is sobering that even for the SNB, where the 'site of action question' has been most intensively investigated, we still do not know exactly what cells testosterone acts on to control neuronal survival. For the BNSTp and SDN-POA, the site of hormone action for controlling cell survival is also not definitively known, although the relevant receptors (estrogen receptors) are expressed in those cell groups perinatally (DonCarlos, 1996; Kelly et al., 2013).

\subsubsection{Novel Molecular Mechanisms in the Hormonal Regulation of Cell Death}

The AVPV is a small cell group located at the rostral extreme of the third ventricle that critically controls the luteinizing hormone surge required for ovulation (reviewed in Herbison, 2008). In contrast to the SNB, BNSTp and SDN-POA, AVPV is larger and contains more cells in female rats and mice than in males (reviewed in Forger, 2009). Nonetheless, hormoneregulated, Bax-dependent cell death is implicated in this sex difference because estradiol increases cell death, up-regulates the Bax and down-regulates $\mathrm{Bcl}-2$ protein expression in the neonatal female rat AVPV (Arai et al., 1996; Tsukahara et al., 2008). Moreover, the sex difference in total cell number in AVPV is eliminated in Bax $-/$ - and $\mathrm{Bcl}-2$ overexpressing mice (Figure 4A; Forger et al., 2004; Zup et al., 2003). Thus, differentiation of AVPV appears to depend on estrogenic induction of apoptosis.

To explore in greater detail the molecular mechanisms underlying the sex difference in AVPV cell death in rats, Petersen and colleagues used targeted apoptosis microarrays and whole transcriptome analysis (Del Pino Sans et al., 2015; Krishnan et al., 2009). The microarrays identified a pathway that is important for controlling cell death in the immune 
system as sex-specifically active in the AVPV of rats; the tumor necrosis factor a receptor 2 (TNFaR2) / nuclear factor kappa-light-chain-enhancer of activated B cells (NFkB) cell survival pathway is more active in AVPV of neonatal females, likely because an inhibitor of this pathway is highly expressed in males (Krishnan et al., 2009). In the transcriptome analysis, they found higher expression of the gene CUG triplet repeat, RNA binding protein 2 (Cugbp2) in the AVPV of newborn male rats, and expression of this gene was increased in AVPV of newborn females 18 hours after estradiol treatment (Del Pino Sans et al., 2015). As Cugbp2 has been implicated in promoting cell death in other systems, this may be part of the molecular mechanism responsible for defeminizing AVPV in males. Thus, while the complete cascade linking testosterone (or an estrogenic metabolite) to cell death is not known for any neural area, work in AVPV has taken us closest to that goal.

\subsection{Cell Genesis after Perinatal Life}

New neurons continue to be generated in some brain regions after the perinatal period and glial cell generation is widespread throughout life (Ninkovic and Gotz, 2013). The addition of new cells, as measured by incorporation of the cell birth marker bromodeoxyuridine (BrdU), has been reported in the SDN-POA, AVPV, and medial amygdala (MeA) of adolescent rats (Ahmed et al., 2008). Although some of the BrdU labeled cells may reflect the turnover of glia or endothelial cells, a subset labels with NeuN, a marker of mature neurons (Ahmed et al., 2008). This challenges the dogma that neurogenesis is a purely pre- or perinatal event in the hypothalamus and amygdala. It is not known whether this phenomenon is unique to adolescence, as other ages were not examined. Sex differences in the total number of BrdUlabeled cells in each region closely mirrored sex differences in the total cross-sectional area of each nucleus. Thus, the number of new cells per unit area in the SDN-POA, AVPV, and MeA appears to be similar in both sexes, suggesting that the new cells may maintain sex differences, 
rather than generating them. Nonetheless, perturbations to this "late" cell genesis could affect sexually dimorphic functions.

\subsection{Differentiation of Phenotype}

Differentiation of phenotype covers a lot of ground, and can refer to differentiation of neurochemistry (e.g., expression of neurotransmitters, peptides, or hormone receptors) or morphology (e.g., soma size, dendritic complexity, number and type of synapses). Many (perhaps most) sex differences in the nervous system are examples of the differentiation of phenotype, even though this term may not be explicitly used by authors discovering or describing the differences.

\subsubsection{Neurochemical Phenotype}

It can be surprisingly difficult to determine whether a given sex difference is due to the differentiation of neurochemical phenotype. For example, there are more neurons expressing the neuropeptide vasopressin in the BNST of males than in females across many vertebrate species (De Vries and Panzica, 2006) and, in rats, perinatal programming by gonadal steroids is one factor that determines the number of BNST cells with the potential to express vasopressin (Wang et al., 1993). This effect of hormones might be due to differentiation of neurochemistry

(e.g., if testosterone causes existing cells to commit to a vasopressinergic fate), but alternatively could be due to cell death (e.g., if testosterone enhances the survival of presumptive vasopressin neurons). A similar puzzle arises when one tries to explain any sex difference in the number of a particular type of cells.

Over 20 year ago, the differentiation of cell phenotype was proposed as the underlying mechanism for sexual differentiation of vasopressin neurons in the BNST (Planas et al., 1995), but a role for cell death could not be ruled out. To test this, we examined the number of vasopressin neurons in $\mathrm{Bcl}-2$ overexpressing and Bax knockout mice. In both cell death mutants, the sex difference persisted with no difference in magnitude compared to that in wild- 
type siblings (De Vries et al., 2008). Although cell death independent of Bcl-2 or Bax has been described (Kroemer and Martin, 2005), that explanation is unlikely here because Bax gene deletion eliminates $>95 \%$ of the naturally-occurring cell death (i.e., not induced by insult or injury) throughout the developing forebrain (Ahern et al., 2013; White et al., 1998). Thus, differential cell death in males and females is unlikely to determine the proportion of cells that becomes vasopressinergic in the BNST.

Similarly, in the POA, immunohistochemistry for the calcium binding protein calbindin defines a cell group that is larger in males and thought to be the mouse equivalent of the rat SDN-POA (Edelmann et al., 2007; Orikasa and Sakuma, 2010). However, the sex difference in the number of calbindin cells in the "mouse SDN-POA" is completely unaffected by Bax gene deletion (Gilmore et al., 2012), suggesting that this difference may be due to the differentiation of phenotype rather than cell death. In the AVPV, females have many more dopaminergic neurons and neurons expressing kisspeptin than do males (Clarkson and Herbison, 2006; Kauffman et al., 2007; Simerly et al., 1985), and these sex differences, too, persist unchanged in Bax knockout mice (Figure 4B, C; Forger et al., 2004; Semaan et al., 2010).

Thus, although cell death may be responsible for sexual differentiation of total cell number in the BNST, SDN-POA and AVPV (Forger et al., 2004), it does not appear to determine the proportion of cells that express specific markers. Throughout development, cell phenotype "decisions" are based in large part on epigenetic modifications that determine the subset of the genome that is transcribed in a given cell. The sex differences in the number of cells expressing vasopressin in the BNST, calbindin in the SDN-POA, and dopamine or kisspeptin in the AVPV may be examples of hormonally controlled epigenetic modifications (see Section 5).

\subsubsection{Morphological Phenotype}


Sex differences have been described in both glial and neuronal morphology that are due to perinatal exposure to gonadal steroids. In the arcuate nucleus of the rat, for example, astrocytes tend to have a bipolar morphology in females, but are more stellate in males (Mong and McCarthy, 1999, 2002). Neonatal treatment of females with testosterone or estradiol, but not with the non-aromatizable androgen dihydrotestosterone permanently masculinizes astrocyte morphology, indicating that the sex difference is due to programming effects of estrogens (Mong and McCarthy, 1999, 2002; Mong et al., 2002). In this case, estrogens appear to act on astrocyte morphology indirectly, by upregulating GABA release from neighboring neurons. Inhibiting GABA synthesis in the arcuate nucleus prevents the estradiol-mediated effects on astrocyte morphology, while administration of a $\mathrm{GABA}_{\mathrm{A}}$ receptor agonist in the first 2 days of life masculinizes female astrocyte morphology (Figure 5A; Mong et al., 2002).

Other examples come from the ventromedial nucleus of the hypothalamus $(\mathrm{VMH})$, which is $25 \%$ larger in male than that in female rats, due to larger soma size and dendritic length of neurons in males. These sex differences are not eliminated by acute manipulations of gonadal steroids, indicating that they are programmed early in development (Griffin and Flanagan-Cato, 2009; Madeira et al., 2001), although the underlying cellular/molecular mechanisms are not known. Neurons in the medial basal hypothalamus (comprised of the $\mathrm{VMH}$ and adjacent structures) of male rats also have a roughly 2 -fold greater dendritic spine density than in females (Schwarz et al., 2008), presumably providing a greater number of sites for excitatory input. Here, the mechanism has been investigated and is thought to involve estradiol-induced glutamate release around the time of birth. Specifically, estradiol treatment of newborn females activates phosphatidylinositol 3-kinase in $\mathrm{VMH}$ neurons, which in turn recruits proteins to the presynaptic membrane that enhance exocytosis and glutamate release (Schwarz et al., 2008). This effect is independent of protein synthesis, suggesting that it does not rely on genomic actions of the estrogen receptor. Glutamate receptor activation at the postsynaptic neuron then 
activates MAP kinase, resulting in increases in spine density and in spinophilin, a protein highly enriched in dendritic spines (Figure 5C; Schwarz et al., 2008).

The POA exhibits what appears on the surface as a very similar sex difference: a roughly 2 -fold higher density of dendritic spines in males, as measured by spinophilin protein expression (Amateau and McCarthy, 2002). Here, however, neonatal estradiol causes the sex difference by up-regulating cyclooxygenase-2, an enzyme responsible for prostaglandin- $\mathrm{E}_{2}$ $\left(\mathrm{PGE}_{2}\right)$ synthesis (Amateau and McCarthy, 2004). $\mathrm{PGE}_{2}$ then binds to prostanoid receptors in post-synaptic cells, which causes increased cAMP, and activation of protein kinase-A (Wright et al., 2008; Wright and McCarthy, 2009). This results in phosphorylation of AMPA-type glutamate receptor subunits and increased insertion of glutamate receptors into the membrane (Lenz et al., 2011). Although not yet directly demonstrated, this may induce the formation and stabilization of dendritic spines (Figure 5B).

Thus, despite superficial similarities, sex differences in morphology may have very different cellular and molecular underpinnings depending on brain region. Even for different compartments of the same cell, the mechanism underlying hormone effects on morphology can differ, as demonstrated in the SNB neuromuscular system. Androgens increase both the size of SNB somas and their dendritic arbors in male rats and mice (Breedlove and Arnold, 1981; Forger and Breedlove, 1987; Kurz et al., 1986). Surprisingly, however, the hormone acts at the target muscles to increase dendritic extent (Rand and Breedlove, 1995), but directly at SNB motoneurons to control soma size (Watson et al., 2001).

\section{Gonad-Independent Effects of the Sex Chromosomes}

Until recently, the prevailing view was that sex chromosomes determine which gonad develops, but that hormones from the gonad do the rest of the "work" as far as sexual differentiation is concerned. It is now clear, however, that there are gonad-independent effects of the sex chromosomes on the brain and behavior. 


\subsection{The Four Core Genotypes (FCG) Mouse Model}

The FCG mouse model has been definitive in establishing gonad-independent effects of sex chromosome complement on the brain and behavior. In this model, the testis-determining gene, Sry, is removed from the $\mathrm{Y}$ chromosome and inserted on an autosome (XY-Sry). By mating $\mathrm{XY}$ - Sry males with normal females, $\mathrm{XX}$ offspring with ovaries or testes, and $\mathrm{XY}$ offspring with ovaries or testes are generated, allowing one to dissociate effects of sex chromosome complement from effects of the gonads (see De Vries et al., 2002 for further details of the model). Caveats of the FCG model are that the XX males and XY- females are not fertile and one can never completely eliminate the possibility of subtle differences in hormone secretion by $X X$ and $X Y$ testes (or $X X$ and $X Y$ ovaries), although none have so far been reported. In addition, Sry itself has effects on the brain in rats (Dewing et al., 2006).

Results from the FCG mouse model confirm that many of the best-studied sex differences in the nervous system depend on gonad type, with no apparent contribution of sex chromosome complement (De Vries et al., 2002). However, midbrain neurons harvested from $\mathrm{XY}$ embryos show more expression of tyrosine hydroxylase, the rate-limiting enzyme of dopamine production, than do neurons from XX embryos, regardless of gonad type (Carruth et al., 2002). This echoes earlier findings by Beyer, Pilgrim and Reisert that sex differences in midbrain and diencephalic dopamine neurons emerge during embryonic life prior to any sex difference in plasma testosterone; in the rats, however, it was genetic females that had greater dopamine levels, TH activity and number of TH immunoreactive cells (Beyer et al., 1992; Beyer et al., 1991).

The sex difference in vasopressin innervation of the lateral septum also partly depends on sex chromosome complement because FCG mice with a $Y$ chromosome have more vasopressin than XX mice, independent of whether they are gonadally male or female (De Vries et al., 2002; Gatewood et al., 2006). Evidence for gonad-independent effects of the sex 
chromosomes has also been found for parental behavior, aggression, pain sensitivity, and social behavior (Cox and Rissman, 2011; Gatewood et al., 2006; Gioiosa et al., 2008).

Seney and colleagues recently used the FCG model to tease apart effects of the gonads and sex chromosomes on sex differences in depression- and anxiety-like behaviors induced by chronic stress. Only gonadal sex influenced depression-like behavior in stressed FCG mice (Seney et al., 2013). For anxiety, however, both the gonad type and sex chromosome complement contributed, and they exerted opposing effects: having testes increased anxietylike behavior (independent of sex chromosome complement), but having an XY genotype decreased anxiety (independent of gonad type; Seney et al., 2013). This supports the prediction by De Vries (2004) that, in some cases, circulating gonadal hormones act to compensate for effects of genetic sex.

Another example of the complex interplay between gonadal hormones and sex chromosome complement comes from a recent study of sex differences in aromatase expression. Hypothalamic neurons from male mice and rats have more aromatase expression and aromatase activity than those of females as early as E15-E16 (Beyer et al., 1994; NegriCesi et al., 2001). Because this is prior to the prenatal testosterone surge, a role for gonadal hormones seems unlikely. Indeed, using the FCG mouse model, Cisternas and colleagues (2015) find that $X Y$ embryos have higher aromatase expression than $X X$ embryos in the stria terminalis and anterior amygdaloid region at E16, independent of gonad type. Because aromatization is required for many effects of testosterone on brain sexual differentiation, this suggests a scenario where sex chromosome complement works in concert with gonadal hormones, i.e., to boost effects of testosterone in some brain regions.

For none of the gonad-independent effects of sex chromosome complement mentioned above have the responsible gene(s) been identified. Obvious possible candidates include $Y$ chromosome genes expressed in males, or a double dosage of $\mathrm{X}$ chromosome genes (particularly those that escape $X$ inactivation) in females (Arnold, 2012). In one approach to 
address this issue, Cox and colleagues (2015) recently demonstrated that mice with only one X chromosome (X0 or $\mathrm{XY}$ ) have more vasopressin expression in the amygdala and are less social than those with two $X$ chromosomes $(X X$ or $X X Y)$, pointing to the dosage of $X$ chromosome gene(s) as responsible for these effects. Because the $\mathrm{X}$ chromosome is inherited asymmetrically (female offspring receive an $\mathrm{X}$ from both the mother and father, whereas male offspring receive an $\mathrm{X}$ only from the father), genes that are parentally imprinted, i.e. expressed unequally from the maternal and paternal allele, are also possible sources of neural sex differences (Davies et al., 2006).

\subsection{Development in the Absence of Gonads}

Another line of evidence for gonad-independent effects of the sex chromosomes comes from mice lacking the gene for steroidogenic factor 1 (SF1), in which no testes or ovaries form. These mice provide an opportunity to examine the development of genetic males and females in the absence of any gonadal hormones. As predicted by the classical view of hormonedependent sexual differentiation, many sex differences in the body, brain and behavior are eliminated in SF1 knockout mice (Budefeld et al., 2008; Majdic and Tobet, 2011). There are exceptions, however. For example, a sex difference in neuronal nitric oxide synthase in the AVPV persists in SF1 knockouts (Budefeld et al., 2008), indicating that this difference is gonad independent. Limitations of the SF1 knockout model are that the adrenal glands also do not form, and there are brain abnormalities in the knockouts that are unlikely to be related to the lack of gonads (Ikeda et al., 1995; Shinoda et al., 1995).

\section{Role of the Immune System}

A decade ago, the immune system was unlikely to have been considered in even a comprehensive review of sexual differentiation of the brain. That has radically changed, with 
several novel findings uncovering important roles for immune cells or immune signaling molecules in aspects of brain sexual differentiation. In the foregoing discussion we have already encountered at least two examples: TNF $\alpha$ R2 / NFKB signaling, usually associated with cell death in the immune system, is implicated in sexual differentiation of AVPV (Section 2.1.2), and $\mathrm{PGE}_{2}$, normally associated with inflammation in the periphery, is required for sexual differentiation of the POA (Section 2.3.2). As discussed below, sex differences in the peripheral immune response may cause differences in the brain, and additional findings point to an essential role for microglia, the innate immune cells of the brain, in sexual differentiation.

\subsection{Effects of the Peripheral Immune System on the Brain}

Males and females often exhibit differences in the peripheral immune activation to a given stimulus, with females generally having a greater response (see Mirandola et al., 2015 for review). This may explain why women have a higher incidence of most autoimmune diseases (Beeson, 1994; Whitacre et al., 1999), including those that affect the brain such as multiple sclerosis (MS). Female mice are also more susceptible than males in a rodent model of MS (experimental autoimmune encephalomyelitis), which is induced by injecting myelin basic protein and immune-boosting agents near peripheral lymph nodes. In the initial phase of the disease, male mice produce fewer lymph node immune cells than do females, and fewer reactive cells that produce inflammatory cytokines (Kim and Voskuhl, 1999). Even if T lymphocytes from females are introduced into mice of both sexes, however, males are still protected from disease onset (Voskuhl et al., 1996). Thus, the periphery of male and female mice responds quite differently to the same disease trigger, which as a consequence exposes the brain to different stimuli.

Sex steroids play an important role in both human MS and the mouse model of the disease (reviewed in Spence and Voskuhl, 2012; Vegeto et al., 2008), but there are also important gonad-independent effects, as demonstrated by studies using the four core genotype 
mice (Section 3). XX mice show a more severe disease course in response to injection of myelin basic protein, regardless of gonad type (Smith-Bouvier et al., 2008). However, when the sex of immune system cells is held constant (e.g., an $\mathrm{XX}$ immune system in an $\mathrm{XX}$ or $\mathrm{XY}$ animal), mice with an XY nervous system show more severe pathology (Du et al., 2014). This may be related to the clinical observation that although MS is more prevalent in women, men have faster disease progression (Voskuhl and Gold, 2012).

\subsection{The Brain's Immune Response}

Rodent studies have recently demonstrated several sex differences in the primary immune cells of the brain. As the principal immunocompetent cells of the central nervous system, microglia constantly survey the parenchyma for any disturbance and, when activated, transition from a highly ramified to a more amoeboid morphology and increase the production of pro-inflammatory molecules (Ransohoff and Brown, 2012; Town et al., 2005). Astrocytes also produce pro-inflammatory signals in response to an injury or immune challenge and are implicated in the neuroinflammation accompanying many neurodegenerative diseases (Ransohoff and Brown, 2012).

The in vitro responses of microglia and astrocytes to lipopolysaccharides (LPS), components of bacterial cell walls that induce a robust immune response, differ depending on whether the glia are harvested from male or female rodents. For example, mRNA levels of proinflammatory cytokines are higher in astrocytes derived from the cortex of neonatal male mice than females, and the inflammatory response is masculinized in glia harvested from newborn females treated with testosterone propionate 24 hours earlier (Santos-Galindo et al., 2011). It is not known whether this reflects permanent, programming effects of testosterone, since longer delays after the hormone exposure were not examined. In a study of similar design, microglia and astrocytes harvested from male rat neonates showed a greater increase in mRNA for the proinflammatory cytokine IL-1 $\beta$ in response to an LPS challenge in vitro than did glia from 
females (Loram et al., 2012). Additionally, estradiol exerted opposite effects on glia harvested from male versus female rat pups: the hormone produced an anti-inflammatory effect on glia from males but a pro-inflammatory effect on glia from females (Loram et al., 2012).

In addition to sex differences in gene expression, differences in the number and morphology of brain immune cells have been reported. Perinatally, most microglia are amoeboid or "stout" in morphology, suggestive of an activated state (Lenz and McCarthy, 2015; Town et al., 2005). Sex differences in microglial colonization are reported on the first day of life in rats, with females having more microglia overall and greater numbers of amoeboid and stout microglia in several brain regions (Schwarz et al., 2012). This trend reverses four days later, with many more microglia overall and more amoeboid and stout microglia in males. At postnatal day 30 and in adulthood, the sex difference again reverses, with females tending to have more microglia, especially those with long, thick processes (Schwarz et al., 2012). Sex differences in microglial gene expression in the absence of any exogenous immune activation have also been reported, but only on postnatal day 3 in mice (Crain et al., 2013).

The function of these shifting sex differences in microglial number, morphology, and gene expression are not known, but may be related to masculinization of the POA. As mentioned above, male rats have more dendritic spines on POA neurons and this sex difference depends on the production of $\mathrm{PGE}_{2}$ (Section 2.3.2; Amateau and McCarthy, 2002). Males also have about a $25 \%$ higher density of microglia and twice as many amoeboid microglia than females in the neonatal POA (Lenz et al., 2013). Production of $\mathrm{PGE}_{2}$, microglial density, and dendritic spine density in the POA all increase in response to neonatal estradiol (Amateau and McCarthy, 2004; Lenz et al., 2013). Co-administration of a microglial inhibitor blocks these effects of estradiol and prevents masculinization of several measures of male sex behavior (Lenz et al., 2013), suggesting that microglia are essential for masculinization of POA morphology and function. 
Microglia may also play a role in sex differences in adulthood. Allodynia (mechanical pain hypersensitivity) resulting from a peripheral nerve injury is dependent on a microglial pathway in males, but a T-cell pathway in females (Sorge et al., 2015). In support, glial inhibitors dose-dependently reverse allodynia in gonadally intact male, but not female mice (Sorge et al., 2015). Microglial inhibition is no longer effective in preventing allodynia in males after castration, indicating that the sex difference is due to acute effects of gonadal hormones. Sex differences in the functioning of microglia extends to allodynia caused by other conditions, such as persistent inflammatory pain (Sorge et al., 2011), and perhaps to disorders with a neuroinflammatory component, such as MS, Alzheimer's disease, depression, and chronic pain, all of which are more prevalent in women than in men (Tonelli et al., 2008; Watkins et al., 2007).

\section{Role of Epigenetics}

The essence of epigenetic regulation is the control of gene activity through changes in the structure of chromatin (DNA and associated histone proteins). Based on this definition, one could argue that steroid hormone action routinely involves "mini" epigenetic events. After binding their respective ligands, steroid receptors recruit proteins with histone modifying activity (Kininis et al., 2007; Kishimoto et al., 2006; Spencer et al., 1997; Tetel, 2009); the histone modifications help to unwind the chromatin in the region of steroid responsive genes, increasing gene transcription. On this basis alone one might predict that hormone-mediated sex differences would require epigenetic mechanisms. Epigenetic modifications are also good candidates for any form of cellular "memory," such as the long term changes in gene expression that must underlie sex differences in morphological or neurochemical cell phenotype in response to gonadal hormone exposure (see Section 2.3).

The best-studied epigenetic marks include DNA methylation, histone acetylation, and histone methylation. Recent work demonstrates that each of these is required for sexual 
differentiation of the brain during development, and/or differs between the brains of male and females (for a more complete discussion, see Forger, 2016; McCarthy and Nugent, 2013). One of the earliest studies examining sex differences in epigenetic marks found that neonatal male mice have more acetylation than do females on lysine residues 9 and 14 of histone 3 , (H3K9/14Ac) and more trimethylation on lysine 9 of histone $3(\mathrm{H} 3 \mathrm{~K} 9 \mathrm{Me} 3)$ in the neonatal cortex and hippocampus (Tsai et al., 2009). Schwarz et al. (2010) found sex differences in DNA methylation of steroid receptor genes, some of which could be reversed by neonatal estradiol treatment of females and therefore are likely to be due to programming effects of steroids. Below we review studies examining the effects of manipulating histone acetylation or DNA methylation on the development of sex differences, as well as those reporting on sex differences in the distribution of specific epigenetic marks across the genome.

\subsection{Effects of Manipulating Epigenetic Mechanisms}

The best-understood histone modification is the covalent addition of acetyl groups to histone tails, which opens chromatin conformation and (usually) increases gene expression (Cosgrove and Wolberger, 2005). Histone deacetylases (HDACs) remove acetyl groups and generally are associated with gene repression. To determine whether the sex difference in volume and cell number of the BNSTp (Section 2.1) requires histone acetylation, we gave subcutaneous injections of a histone deacetylase inhibitor to mice on the first two days of life. Animals were sacrificed at weaning and their brains examined. We found that neonatal HDAC inhibition prevented masculinization of the BNST in both males and testosterone treated females, while having no effect on control females (Murray et al., 2009). In a study of similar design, intracerebroventricular administration of an HDAC inhibitor to newborn rats blocked masculinization of sexual behavior in adulthood (Matsuda et al., 2011). These studies suggest that histone deacetylation (and hence, presumably, the repression of some gene or genes) is required for masculinization of BNST morphology and copulatory behavior in rodents. 
DNA methylation is usually associated with gene repression and is catalyzed by a family of DNA methyltransferases. As described in Section 2.3.2, dendritic spine density is greater in the POA of male than of female rats and is masculinized in females treated neonatally with estradiol (Amateau and McCarthy, 2002). Nugent and colleagues (2015) recently examined the effect of inhibiting DNA methyltransferases during the first two days of life on dendritic spine density and male copulatory behavior in rats. The transient blockade of DNA methylation increased spine density in the POA and male copulatory behavior in adulthood in females, with little to no effect in males. This suggests that male-like development is normally repressed in females by gene methylation (Nugent et al., 2015).

\subsection{Sex Differences in Epigenetic Marks Across the Genome}

In another approach, several groups have recently reported on the distribution of specific epigenetic marks across the genome in the brains of males and females. Ghahramani and colleagues (2014) used reduced representation bisulfite sequencing to examine sex differences and effects of neonatal testosterone on the DNA methylome of the striatum and BNST/POA of mice. Although fewer than 100 genes were differentially methylated when comparing control males and females on postnatal day 4, roughly 1,000 genes were differentially methylated in adulthood. A similar pattern was seen when comparing control females with females given a single injection of testosterone on the day of birth (Figure 6). Because all animals that were sacrificed as adults had been gonadectomized pre-pubertally and given identical silastic capsules filled with testosterone, the sex differences seen in adults cannot be attributed to acute effects of gonadal steroids, but instead reflect late-emerging effects of neonatal hormone exposure.

In addition, there was a strong sex asymmetry in the distribution of the genes with differential methylation in males and females: $\sim 90 \%$ of the differentially methylated regions 
across all autosomes were more methylated in males (or testosterone-treated females; Figure 6; Ghahramani et al., 2014).

A second genome-wide study identified about 250 genes associated with a significant sex difference in histone-3 lysine-4 trimethylation (H3K4me3; a modification often found at the transcription start site of active genes) in the adult mouse BNST/POA. The genes identified in this study also showed a sex bias, with about $70 \%$ of them having more H3K4me3 in females (Shen et al., 2015). In addition, in neither study was there a good correlation between sex differences in the epigenetic modification and gene expression (Ghahramani et al., 2014; Shen et al., 2015). This is perhaps not surprising because studies comparing gene transcription in males and females reveal relatively few genes with sexually dimorphic expression, at least in homogenates of heterogeneous brain areas such as "hypothalamus" or "prefrontal cortex" (Weickert et al., 2009; Xu et al., 2012). The DNA methylation and H3K4Me3 studies suggest that even when gene expression is similar in males and females, the epigenetic underpinnings of that expression may differ.

\subsection{Sex Chromosomes and Epigenetics}

By far the most pervasive sex difference involving epigenetics is the process of random $\mathrm{X}$ inactivation. The silencing of one $\mathrm{X}$ chromosome takes place in every cell of female mammals and in no cells of males, and occurs via massive epigenetic modifications to the inactivated chromosome. The generally accepted purpose of $X$ inactivation is to make gene expression more similar in males and females by equalizing the dosage of $\mathrm{X}$ genes. However, the inactivation state must continually be maintained (Csankovszki et al., 2001; Yang et al., 2015), and this places an ongoing demand on the epigenetic machinery in XX cells. Drosophila do not have $\mathrm{X}$ chromosome inactivation, but large portions of the $\mathrm{Y}$ chromosome are inactivated and this has been shown to affect the expression of autosomal genes (Francisco and Lemos, 2014), perhaps because elements of the epigenetic machinery (e.g., enzymes that place inactivating 
marks on the $\mathrm{Y}$ ) are in limited supply. As of yet, sex differences in autosomal gene expression due to $\mathrm{X}$ chromosome inactivation have not been demonstrated in the mammalian brain, but could well be in the future (Wijchers et al., 2010).

The complex interplay that is possible between epigenetic mechanisms and sex chromosome complement is illustrated by considering two X-linked genes: $K d m 5 c$ and $K d m 6 a$. Both of these genes escape inactivation in some mouse tissues, and have higher expression in the brains of female mice than in males (Bonthuis and Rissman, 2013; Shen et al., 2015; Xu et al., 2008). Genes that escape X-chromosome inactivation are often associated with increased H3K4me3 (Khalil and Driscoll, 2007) and, indeed, both Kdm5c and Kdm6a were identified as having elevated H3K4me3 peaks in the female BNST/POA in the study mentioned above (Shen et al., 2015). The plot thickens when it is recognized that the protein products of these genes themselves alter histone methylation. $\mathrm{Kdm} 5 \mathrm{c}$ is a lysine demethylase that removes methyl groups from the lysine 4 position of histone tails (Iwase et al., 2007). Kdm6a, on the other hand, is a transcriptional activator that removes repressive histone methylation marks at H3K27 (Hong et al., 2007). Thus, this is a case where an activating histone mark (H3K4me3) and sex chromosome complement combine to produce a sex differences in the neural expression of two genes whose protein products, in turn, may alter the histone methylation associated with a host of other genes.

\section{Environment-Brain Interactions}

An individual's external environment can also play an important role in the development of neural sex differences. The number of possible environmental influences are limitless; here we present three cases of environment-brain interactions that have been studied in some detail and that offer different perspectives. Using the example of maternal care in rats (Section 6.1) we examine how interactions with conspecifics can contribute to sex differences in the nervous 
system. We next consider how interactions with other species may lead to sex-specific effects on the brain and behavior by considering effects of the intestinal flora on the brain (Section 6.2). Above (Section 4) we saw that response to an immune challenge can vary by sex; in Section 6.3 we explore several aspects of the response to other environmental stressors that illustrate at the molecular level how male and female brains may respond differently to an identical external stimulus.

\subsection{Interactions with Conspecifics - Maternal care}

Many sex differences in the brain are shaped early in postnatal development, when most mammalian offspring are completely dependent on maternal care for growth and survival. In rats, anogenital licking is part of the maternal repertoire, and male pups receive more licking than females, due to testosterone-regulated olfactory cues present in the male urine (Moore, 1985). This hormone-dependent difference in maternal stimulation is linked to the development of cellular, molecular, and behavioral sex differences in the offspring.

In the neonatal rat POA, estrogen receptor alpha (ERa) mRNA and protein levels are lower in males than in females, and a corresponding sex difference in DNA methylation of the ERa promoter region is seen, with greater methylation in males (Figure 7; Kurian et al., 2010). The sex differences in ERa expression and methylation are eliminated when simulated maternal grooming (i.e., stroking the anogenital region with a paintbrush) is increased in females (Figure 7; Kurian et al., 2010). Similarly, ERa expression and gene methylation patterns in the amygdala are masculinized in female rats by increased simulated maternal grooming (Edelmann and Auger, 2011). It is noteworthy that an earlier study on the effects of natural variations of maternal care (low versus high maternal licking) on adult female offspring found the opposite effect; namely, females raised by high licking mothers showed increased ERa expression in the POA together with decreased methylation of the ERa promoter (Champagne et al., 2006). The discrepancies between these reports may relate to differences in experimental 
paradigm, age of subjects, or brain areas sampled. Nevertheless, together these studies

underscore the influential role that early experience may play in regulating sex differences in the brain.

Variations in maternal care also impact the development of sex differences in the spinal cord. When anogenital licking is decreased, the number, soma size, and dendritic length of SNB motoneurons are reduced in male offspring (Lenz and Sengelaub, 2006; Moore et al., 1992). The mechanisms underlying these effects are yet to be determined but oxytocin may play a role. Anogenital stimulation induces oxytocin release from the hypothalamus into the lumbosacral spinal cord, where the SNB is located (Lenz and Sengelaub, 2010). Once in the spinal cord, oxytocin could alter SNB neuronal morphology via effects on glutamatergic signaling (Lenz and Sengelaub, 2010): oxytocin stimulates glutamatergic neurons in vitro (Jo et al., 1998), and in vivo blockade of NMDA glutamate receptors reduces SNB dendritic length (Hebbeler et al., 2002).

\subsection{Interactions with other Species - The Gut Microbiota}

Mammals live in symbiotic relationships with other species, most intimately with the microbiota that populate all of our body surfaces that contact the outside world. The gut microbiota, the collection of microorganisms living in our intestines, releases molecules such as short chain fatty acids, neurotransmitter precursors (e.g. tryptophan), and neurohormones (e.g., serotonin), that may influence brain physiology and behavior (reviewed in Clarke et al., 2014). Evidence for this comes from studies comparing mice with a normal microbiota (conventionally colonized) with those devoid of microbiota (germ free). Female and male germ free mice show reduced anxiety-like behaviors and altered levels of stress hormones compared to conventionally colonized mice, and these effects can be reversed by fecal transfer from conventional to germ free animals (reviewed in Foster and McVey Neufeld, 2013). However, the microbiota of male and female mice may differ, even when they are given the same diet and 
housing conditions (Markle et al., 2013). This raises the possibility that some of the observed sex differences in anxiety-like behaviors (see Section 6.3) may be caused by the microbiota.

The microbiota present early in life also may contribute to the masculinization of the hippocampal serotonin system. Adult female mice have higher levels of serotonin and its main metabolite, 5-hydroxyindoleacetic acid (5-HIAA), in the hippocampus than do males (Clarke et al., 2013). Because serotonin decreases hippocampal levels of glucocorticoid receptors

(Semont et al., 2000), this may contribute to the lower hypothalamic-pituitary-adrenal (HPA) axis negative feedback sensitivity in females (Goel and Bale, 2010). The sex differences in serotonin and 5-HIAA depend on the microbiome because they disappear when mice are raised germ free (Clarke et al., 2013). Microbiota transfer after weaning in germ free animals does not alter hippocampal serotonin or 5-HIAA levels (Clarke et al., 2013), suggesting that the exposure must occur early in development.

Preliminary results also suggest an effect of the microbiota on the development of sex differences in vasopressin innervation of brain regions involved in anxiety. For example, male mice normally have more vasopressin immunoreactivity than females in the mediodorsal nucleus of the thalamus, but this difference is significantly reduced in adult germ free mice (Peters et al., 2015). Similar effects are not seen in other vasopressin projection areas (Peters et al., 2015), suggesting that the microbiota may have region-specific effects on sex differences in the brain.

Our understanding of the gut-brain axis is in its infancy, and much still needs to be done to identify the mechanisms underlying effects of the microbiota on sexual differentiation of the brain. The regulation of steroid hormones is one potential mechanism, however, as microbiota can alter testosterone levels in host mice (Markle et al., 2013; Yurkovetskiy et al., 2013), and a microbe commonly found in the human gut has been shown to synthesize at least one androgen, i.e., 11ß-hydroxyandrost-4-ene-3,17-dione (11 $\beta$-OHA; Ridlon et al., 2013). 


\subsection{Sexually Dimorphic Responses to the Same Stimuli - The Stress Response}

Twice as many women as men are affected by stress-related disorders such as anxiety and depression. These sex differences emerge at puberty and are less prominent after menopause, suggesting a role for sex steroid hormones (Bebbington et al., 2003; Kessler, 2003; Mechakra-Tahiri et al., 2010; Sonnenberg et al., 2000). In fact, treatments that change the levels of gonadal steroids alter the severity of, and risk for, stress-related disorders (DiBlasio et al., 2008; Miller et al., 2009). The study of stress-related neural substrates in rodents has revealed that sex differences exist at the cellular and molecular levels in key mediators of the stress response, including the HPA axis, locus coeruleus, and hippocampus.

\subsubsection{Sex Differences in the HPA Axis}

The stress response starts with the release of corticotropin-releasing factor (CRF) from the paraventricular nucleus of the hypothalamus (PVN), which stimulates the release of adrenocorticotropic hormone (ACTH) from the pituitary, and glucocorticoids from the adrenal glands; the latter then limits the stress response by negatively feeding back at the level of the hippocampus, hypothalamus and pituitary. Stressors also induce the release of CRF by the PVN and limbic regions into the central nervous system. CRF and its receptor 1 (CRF1) are considered paramount mediators of stress-related psychopathology because altered expression of both have been linked to the development of conditions such as post-traumatic stress disorder and major depression (Banki et al., 1987; Bremner et al., 1997; Merali et al., 2004; Nemeroff et al., 1984; Wang et al., 2008).

Sex differences in the HPA axis appear largely due to acute effects of gonadal hormones. In rodents, males generally show lower levels of ACTH and glucocorticoids under both basal and stress conditions (Critchlow et al., 1963; Handa et al., 1994; Kitay, 1961), but castration increases hypothalamic CRF secretion and CRF neuron numbers in the PVN, and treatment with dihydrotestosterone (a non-aromatizable androgen) prevents these changes 
(Bingaman et al., 1994). Conversely, estradiol treatment of gonadectomized females increases ACTH and glucocorticoids under basal and stress conditions (Burgess and Handa, 1992). Estrogens may also inhibit negative feedback and termination of the stress response (Burgess and Handa, 1992, 1993). Thus, androgens and estrogens may regulate stress hormone levels in opposite directions (Bao et al., 2006) and, by acting at different levels of the HPA axis, circulating estrogens may make females more susceptible to stressors.

The precise molecular mechanisms of gonadal hormone action on the HPA axis are yet to be identified, but female rats have a higher basal level of CRF mRNA in the PVN than do males (Duncko et al., 2001; Viau et al., 2005). The promoter region of the CRF gene has both estrogen and androgen response elements (Bao et al., 2005; Vamvakopoulos and Chrousos, 1993), and CRF-producing neurons in the PVN express androgen and estrogen receptors (Bao et al., 2006; Bao et al., 2005). Thus, effects of gonadal hormones on CRF production may be direct. Epigenetic mechanisms may also contribute to sex differences in the HPA axis response to stress: in the rat PVN, for example, chronic mild stress increases DNA methylation of the CRF gene promoter region only in females (Sterrenburg et al., 2011).

\subsubsection{Locus Coeruleus (LC) and Hippocampus}

The LC is the source of most norepinephrine in the brain. As a key regulator of arousal and attention (reviewed in Aston-Jones and Cohen, 2005), the LC is implicated in the hyperarousal often observed in stress-related disorders (Gold and Chrousos, 2002; Koob, 1999; Southwick et al., 1999). CRF-producing neurons in the PVN project to the LC (Reyes et al., 2005), and CRF alters the firing of LC neurons in rats of both sexes (Curtis et al., 2006; Jedema and Grace, 2004; Reyes et al., 2005). Morphologically, however, LC neurons of females have more extensive and complex dendritic trees, and receive more synaptic inputs, which may render them more responsive to stress-related stimuli (Bangasser et al., 2011). The expansive LC dendrites of females also spread beyond the LC to regions that receive inputs from brain 
areas processing autonomic input, emotion, and nociception, which could further enhance the response of female LC neurons to arousal (Bangasser et al., 2011).

Functional studies have identified sex differences in the LC that are triggered or enhanced by stressors. For example, a sex difference in LC firing emerges following stressrelated stimulation, with females having a greater response to the same stimulus than males (Curtis et al., 2006). A remarkable sex difference also exists in trafficking of CRF receptors in response to stress. Under unstressed conditions, CRF1 in LC neurons of males can be detected in the cytoplasm and at the cell membrane, whereas in females the receptor is restricted to the cytoplasm; stress drives CRF1 from the cell membrane to the cytoplasm in males but has the opposite effect in females (Bangasser et al., 2010; Reyes et al., 2006). This difference in receptor trafficking may make females more sensitive to further CRF signaling. $\beta$-arrestin 2 and G protein receptor kinases are thought to regulate this sex difference by uncoupling CRF1 from membrane-associated G proteins, thereby inducing internalization by endocytosis (reviewed in Luttrell and Lefkowitz, 2002). Support for this mechanism comes from immunoprecipitation studies using rat cortical tissue: under basal conditions, there is no sex difference in the association of $\beta$-arrestin 2 and CRF1, but stress increases this association in males, with no change in females (Bangasser et al., 2010).

The association between CRF1 and $\beta$-arrestin 2 has important implications because it leads to the activation of different receptor signaling pathways by CRF under stress conditions (Figure 8; Valentino et al., 2013). As a result, different cellular responses are elicited by stress in males and females, which in turn may lead to sex-specific physiological and behavioral outcomes in both health and disease (Figure 8). The sex differences in the LC also highlight how a common experience, such as a stressful event, can induce sex-specific effects at the cellular level and molecular levels. Even in cases where stress hormone levels and CRF receptors do not differ between the sexes, the response to a stressor may differ. 
The hippocampal endocannabinoid system provides another example of sex-specific molecular signaling in a system implicated in the stress response (reviewed in Hill and Patel, 2013). Although controversial, cannabinoid treatment is currently being used in some parts of the United States to treat conditions such as post-traumatic stress disorder (e.g., Greer et al., 2014). In rats, estradiol suppresses GABAergic inhibitory synaptic transmission in hippocampal slice cultures of female, but not of male rats, and does so by altering postsynaptic endocannabinoid production, which in turn suppresses GABA release by the presynaptic cell (Huang and Woolley, 2012). Tabatadze and colleagues (2015) recently described the molecular events underlying this sex-specific effect on neural transmission. In females, estradiol induces an association between ERa and the metabotropic glutamate receptor 1 (mGluR1), which leads to the activation of phospholipase $\mathrm{C}$, which in turn generates inositol 1,4,5-trisphosphate (IP3), activates the IP3 receptor (IP3R), and stimulates $\mathrm{Ca}^{2+}$ release, leading to endocannabinoid synthesis and release from the postsynaptic cell. In males, the response of this pathway to estradiol is greatly reduced (Tabatadze et al., 2015). Interestingly, there is no sex difference in basal levels of ERa, mGluR1, IP3, or IP3R (Tabatadze et al., 2015), again demonstrating that even when key players in a signaling pathway are expressed at similar levels in males and females, there may still be a sex-specific response.

\section{Uncomfortable revelations about our favorite models of sexual differentiation.}

As may be clear from the previous sections, one of the most common ways to test whether a given sex difference is due to programming effects of gonadal steroids is to treat female rodents with testosterone or estradiol neonatally. Recent studies, however, reveal a discomforting truth: these treatments may not produce anything close to a normal male at the epigenome or transcriptome level. In the study by Ghahramani and colleagues (2014; Section 5.2), for example, treatment of female mice with testosterone on the day of birth masculinized the DNA methylome in the BNSTp and striatum in adulthood. Although the effect was highly 
statistically significant, the methylation status of only a minority of the genes that were affected by neonatal testosterone treatment of females (36\% and $47 \%$ for the BNST/POA and striatum, respectively) also differed in methylation between normal males and females. At the transcriptome level, Del Pino Sans (2015) recently found 89 genes that were expressed at different levels in the AVPV of neonatal male and female rats, but $>300$ genes that were significantly altered by neonatal estradiol treatment of females. More troubling, there were only 6 genes in common between the two lists! In other words, in terms of gene expression, fewer than $2 \%$ of the genes altered by estradiol-treatment of females also differed between the sexes.

On one hand, it is perhaps not surprising that a single injection of estradiol or testosterone does not perfectly mimic the complex hormone exposure of normal males, which begins prenatally, occurs in two discrete peaks, and may involve a cocktail of gonadal secretions. Moreover, the doses of steroid administered to newborn females are often pharmacological, and any gonad-independent contribution of the sex chromosomes will not be mimicked by a hormone injection. However, these studies reveal that masculinized females may be more like a "third sex" than like males. It is perhaps amazing that for so many dependent variables, neonatal testosterone (or estradiol) produces a phenotype that does not differ significantly from normal males. This may be related to the "canalization" idea first proposed by Waddington (1959) and adapted for sexual differentiation by McCarthy and colleagues (2015): development is funneled, or canalized, into one of two binary outcomes - male or female. With respect to the methylome and transcriptome examples above, perhaps only a few key genes need to be appropriately regulated in order to generate normal male development. Such canalization could provide robustness in the face of environmental or genetic variation.

\section{Where do we go from here?}


The foregoing discussion suggests several interrelated themes that have emerged from recent studies and are likely to continue to shape the field of brain sexual differentiation. These include the roles of non-neuronal cells, the immune system, and the environment.

Until recently, the only non-neuronal cells generally considered when discussing brain sex differences were gonadal cells. Muscles were sometimes included for those of us interested in the sexual differentiation of SNB motoneurons (Section 2.1.1), and sex differences in the number or morphology of astrocytes have been reported in multiple brain regions of rodents over the past 25 years (e.g., Arias et al., 2009; Collado et al., 1995; Johnson et al., 2008; Mong et al., 1996; Suárez et al., 1992). More recent is the report of sex differences in microglia (Schwarz et al., 2012), and the evidence that glia play essential roles in the development of sex differences in neuronal morphology and behavior (Sections 2.3.2 and 4.2). Recent findings also suggest that glia are likely to underlie sex differences in neuroinflammation and neuroinflammatory disorders (e.g., Acaz-Fonseca et al., 2015; Loram et al., 2012).

In addition to immune cells residing within the brain, there are sex differences in peripheral immune responses that can affect normal brain function and the susceptibility to disease (De Vries and Forger, 2015; Mirandola et al., 2015; Spence and Voskuhl, 2012). Moreover, just recently, functional lymphatic vessels were discovered that are embedded in the dura and drain to cervical lymph nodes (Louveau et al., 2015). Although it is too soon to know the implications of this finding for neural sex differences (or any brain function), it challenges the long-held belief that the central nervous system lacks lymphatic vasculature, and suggests we still have much to learn at the intersection of brains and immunity.

However, this is just the start; many other tissues are likely to be important contributors to neural differentiation. For example, although we do not normally think of the liver or adipose tissue as being very sexually dimorphic, the expression of $72 \%$ of all genes surveyed in the liver and $68 \%$ of those in adipose tissue differ between adult male and female mice (Yang et al., 2006). These organs have efferent and afferent connections with the central nervous system, 
and produce hormones and other products that reach the brain. All organs in the body are sexually differentiated to some extent and the brain must operate in the resultant sexually dimorphic milieu. The whole body needs to be considered to fully understand sexual differentiation of the brain and we have recently (somewhat tongue-in-cheek) coined the term "the SexOrganome" to capture this idea (Figure 9; De Vries and Forger, 2015). Future investigations may start to incorporate some of these influences.

Factors from outside of the body, or at the interface of the environment and the body such as the microbiome, also sex-dependently influence the brain (Section 6). To the extent that environmental effects are long-lived, the "memory" for these exposures and experiences generally involve epigenetics, so it is likely that we will see more roles for epigenetics in brain sexual differentiation. The sex biases observed in genes with sex differences in DNA methylation or histone modifications (Section 5.2) suggest that stressors, experiences, drugs, or diseases that preferentially target one type of epigenetic mechanism may have different effects in males and females.

Progress in the field of sexual differentiation may also depend on moving beyond the traditional model species, i.e., mice and rats. Although the study of these species has tremendously increased our knowledge of cellular and molecular mechanisms underlying sex differences in the brain, the inclusion of novel model organisms could shed new light on questions that cannot be answered using traditional models. Work in a highly social species, the naked mole-rat, has already suggested that the "rules" of sexual differentiation of the brain may differ depending on life history traits (Holmes et al., 2009). Where our own species is concerned, it is remarkable that we still have only a shaky understanding of such basic questions as the relative contributions of estrogens and androgens in the masculinization of the brain, based mostly on case studies and inferences, but few direct tests.

These are some of the directions that can be predicted based on recent thrusts in the field of sexual differentiation, but as mentioned in first paragraph of this review, we may be at a 
turning point: as more neuroscientists include both sexes in their study designs, we can anticipate a surge of new discoveries of neural sex differences. Many of these are likely to be made by investigators new to the field, who will bring a fresh perspective and may lead us in directions impossible to envisage today.

\section{Acknowledgements}

We thank Geert J. de Vries, Mary K. Holder, and James J. Taylor for comments on an earlier version of this manuscript. D. Ashley Monks generously shared data. Work of the authors discussed in this review was supported by NIMH R01-068482 and NSF IOS-0642050 (to NGF). 


\section{References}

Acaz-Fonseca, E., Duran, J.C., Carrero, P., Garcia-Segura, L.M., Arevalo, M.A., 2015. Sex differences in glia reactivity after cortical brain injury. Glia. 63 (11), 1966-1981.

Ahern, T.H., Krug, S., Carr, A.V., Murray, E.K., Fitzpatrick, E., Bengston, L., McCutcheon, J., De Vries, G.J., Forger, N.G., 2013. Cell death atlas of the postnatal mouse ventral forebrain and hypothalamus: effects of age and sex. J Comp Neurol. 521 (11), 2551-2569.

Ahmed, E.I., Zehr, J.L., Schulz, K.M., Lorenz, B.H., DonCarlos, L.L., Sisk, C.L., 2008. Pubertal hormones modulate the addition of new cells to sexually dimorphic brain regions. Nat Neurosci. 11 (9), 995-997.

Allen, L.S., Gorski, R.A., 1990. Sex difference in the bed nucleus of the stria terminalis of the human brain. J Comp Neurol. 302 (4), 697-706.

Amateau, S.K., McCarthy, M.M., 2002. A novel mechanism of dendritic spine plasticity involving estradiol induction of prostaglandin-E2. J Neurosci. 22 (19), 8586-8596.

Amateau, S.K., McCarthy, M.M., 2004. Induction of $\mathrm{PGE}_{2}$ by estradiol mediates developmental masculinization of sex behavior. Nat Neurosci. 7 (6), 643-650.

Arai, Y., Sekine, Y., Murakami, S., 1996. Estrogen and apoptosis in the developing sexually dimorphic preoptic area in female rats. Neurosci Res. 25 (4), 403-407.

Arias, C., Zepeda, A., Hernandez-Ortega, K., Leal-Galicia, P., Lojero, C., Camacho-Arroyo, I., 2009. Sex and estrous cycle-dependent differences in glial fibrillary acidic protein immunoreactivity in the adult rat hippocampus. Horm Behav. 55 (1), 257-263. 
Arnold, A.P., 2012. The end of gonad-centric sex determination in mammals. Trends Genet. 28 (2), 55-61.

Aston-Jones, G., Cohen, J.D., 2005. An integrative theory of locus coeruleus-norepinephrine function: adaptive gain and optimal performance. Annu Rev Neurosci. 28, 403-450.

Aussel, C., Masseyeff, R., 1983. Comparative binding properties of rat and human alphafetoproteins for arachidonic acid and estradiol. Res Commun Chem Pathol Pharmacol. 42 (2), 261-269.

Bakker, J., De Mees, C., Douhard, Q., Balthazart, J., Gabant, P., Szpirer, J., Szpirer, C., 2006. Alpha-fetoprotein protects the developing female mouse brain from masculinization and defeminization by estrogens. Nat Neurosci. 9 (2), 220-226.

Bakker, J., De Mees, C., Szpirer, J., Szpirer, C., Balthazart, J., 2007. Exposure to oestrogen prenatally does not interfere with the normal female-typical development of odour preferences. J Neuroendocrinol. 19 (5), 329-334.

Bangasser, D.A., Curtis, A., Reyes, B.A., Bethea, T.T., Parastatidis, I., Ischiropoulos, H., Van Bockstaele, E.J., Valentino, R.J., 2010. Sex differences in corticotropin-releasing factor receptor signaling and trafficking: potential role in female vulnerability to stress-related psychopathology. Mol Psychiatry. 15 (9), 877, 896-904.

Bangasser, D.A., Valentino, R.J., 2012. Sex differences in molecular and cellular substrates of stress. Cell Mol Neurobiol. 32 (5), 709-723.

Bangasser, D.A., Zhang, X., Garachh, V., Hanhauser, E., Valentino, R.J., 2011. Sexual dimorphism in locus coeruleus dendritic morphology: a structural basis for sex differences in emotional arousal. Physiol Behav. 103 (3-4), 342-351. 
Banki, C.M., Bissette, G., Arato, M., O'Connor, L., Nemeroff, C.B., 1987. CSF corticotropinreleasing factor-like immunoreactivity in depression and schizophrenia. Am J Psychiatry. 144 (7), 873-877.

Bao, A.M., Fischer, D.F., Wu, Y.H., Hol, E.M., Balesar, R., Unmehopa, U.A., Zhou, J.N., Swaab, D.F., 2006. A direct androgenic involvement in the expression of human corticotropin-releasing hormone. Mol Psychiatry. 11 (6), 567-576.

Bao, A.M., Hestiantoro, A., Van Someren, E.J., Swaab, D.F., Zhou, J.N., 2005. Colocalization of corticotropin-releasing hormone and oestrogen receptor-alpha in the paraventricular nucleus of the hypothalamus in mood disorders. Brain. 128 (Pt 6), 1301-1313.

Bebbington, P., Dunn, G., Jenkins, R., Lewis, G., Brugha, T., Farrel, M., Meltzer, H., 2003. The influence of age and sex on the prevalence of depressive conditions: report from the National Survey of Psychiatric Morbidity. Int Rev Psychiatr. 15, 74-83.

Beery, A.K., Zucker, I., 2011. Sex bias in neuroscience and biomedical research. Neurosci Biobehav Rev. 35 (3), 565-572.

Beeson, P.B., 1994. Age and sex associations of 40 autoimmune diseases. Am J Med. 96 (5), 457-462.

Beyer, C., Eusterschulte, B., Pilgrim, C., Reisert, I., 1992. Sex steroids do not alter sex differences in tyrosine hydroxylase activity of dopaminergic neurons in vitro. Cell Tissue Res. $270(3), 547-552$.

Beyer, C., Green, S.J., Hutchison, J.B., 1994. Androgens influence sexual differentiation of embryonic mouse hypothalamic aromatase neurons in vitro. Endocrinology. 135 (3), 1220-1226. 
Beyer, C., Pilgrim, C., Reisert, I., 1991. Dopamine content and metabolism in mesencephalic and diencephalic cell cultures: sex differences and effects of sex steroids. J Neurosci. 11 (5), 1325-1333.

Bingaman, E.W., Magnuson, D.J., Gray, T.S., Handa, R.J., 1994. Androgen inhibits the increases in hypothalamic corticotropin-releasing hormone $(\mathrm{CRH})$ and $\mathrm{CRH}$-immunoreactivity following gonadectomy. Neuroendocrinology. 59 (3), 228-234.

Blanchard, D.C., Griebel, G., Blanchard, R.J., 1995. Gender bias in the preclinical psychopharmacology of anxiety: male models for (predominantly) female disorders. J Psychopharmacol. 9 (2), 79-82.

Blaschke, A.J., Weiner, J.A., Chun, J., 1998. Programmed cell death is a universal feature of embryonic and postnatal neuroproliferative regions throughout the central nervous system. $J$ Comp Neurol. 396 (1), 39-50.

Bonthuis, P.J., Rissman, E.F., 2013. Neural growth hormone implicated in body weight sex differences. Endocrinology. 154 (10), 3826-3835.

Bowers, J.M., Waddell, J., McCarthy, M.M., 2010. A developmental sex difference in hippocampal neurogenesis is mediated by endogenous oestradiol. Biol Sex Differ. 1 (1), 8.

Breedlove, S.M., Arnold, A.P., 1981. Sexually dimorphic motor nucleus in the rat lumbar spinal cord: response to adult hormone manipulation, absence in androgen-insensitive rats. Brain Res. 225 (2), 297-307.

Bremner, J.D., Licinio, J., Darnell, A., Krystal, J.H., Owens, M.J., Southwick, S.M., Nemeroff, C.B., Charney, D.S., 1997. Elevated CSF corticotropin-releasing factor concentrations in posttraumatic stress disorder. Am J Psychiatry. 154 (5), 624-629. 
Budefeld, T., Grgurevic, N., Tobet, S.A., Majdic, G., 2008. Sex differences in brain developing in the presence or absence of gonads. Dev Neurobiol. 68 (7), 981-995.

Burgess, L.H., Handa, R.J., 1992. Chronic estrogen-induced alterations in adrenocorticotropin and corticosterone secretion, and glucocorticoid receptor-mediated functions in female rats. Endocrinology. 131 (3), 1261-1269.

Burgess, L.H., Handa, R.J., 1993. Estrogen-induced alterations in the regulation of mineralocorticoid and glucocorticoid receptor messenger RNA expression in the female rat anterior pituitary gland and brain. Mol Cell Neurosci. 4 (2), 191-198.

Byne, W., Lasco, M.S., Kemether, E., Shinwari, A., Edgar, M.A., Morgello, S., Jones, L.B., Tobet, S., 2000. The interstitial nuclei of the human anterior hypothalamus: an investigation of sexual variation in volume and cell size, number and density. Brain Res. 856 (1-2), 254-258.

Carruth, L.L., Reisert, I., Arnold, A.P., 2002. Sex chromosome genes directly affect brain sexual differentiation. Nat Neurosci. 5 (10), 933-934.

Champagne, F.A., Weaver, I.C., Diorio, J., Dymov, S., Szyf, M., Meaney, M.J., 2006. Maternal care associated with methylation of the estrogen receptor-alpha1b promoter and estrogen receptor-alpha expression in the medial preoptic area of female offspring. Endocrinology. 147 (6), 2909-2915.

Chung, W.C., Swaab, D.F., De Vries, G.J., 2000. Apoptosis during sexual differentiation of the bed nucleus of the stria terminalis in the rat brain. J Neurobiol. 43 (3), 234-243.

Cisternas, C.D., Tome, K., Caeiro, X.E., Dadam, F.M., Garcia-Segura, L.M., Cambiasso, M.J., 2015. Sex chromosome complement determines sex differences in aromatase expression and 
regulation in the stria terminalis and anterior amygdala of the developing mouse brain. Mol Cell Endocrinol. 414, 99-110.

Clarke, G., Grenham, S., Scully, P., Fitzgerald, P., Moloney, R.D., Shanahan, F., Dinan, T.G., Cryan, J.F., 2013. The microbiome-gut-brain axis during early life regulates the hippocampal serotonergic system in a sex-dependent manner. Mol Psychiatry. 18 (6), 666-673.

Clarke, G., Stilling, R.M., Kennedy, P.J., Stanton, C., Cryan, J.F., Dinan, T.G., 2014. Minireview: Gut microbiota: the neglected endocrine organ. Mol Endocrinol. 28 (8), 1221-1238.

Clarkson, J., Herbison, A.E., 2006. Postnatal development of kisspeptin neurons in mouse hypothalamus; sexual dimorphism and projections to gonadotropin-releasing hormone neurons. Endocrinology. 147 (12), 5817-5825.

Collado, P., Beyer, C., Hutchison, J.B., Holman, S.D., 1995. Hypothalamic distribution of astrocytes is gender-related in Mongolian gerbils. Neurosci Lett. 184 (2), 86-89.

Cosgrove, M.S., Wolberger, C., 2005. How does the histone code work? Biochem Cell Biol. 83 (4), 468-476.

Cox, K.H., Quinnies, K.M., Eschendroeder, A., Didrick, P.M., Eugster, E.A., Rissman, E.F., 2015. Number of X-chromosome genes influences social behavior and vasopressin gene expression in mice. Psychoneuroendocrino. 51, 271-281.

Cox, K.H., Rissman, E.F., 2011. Sex differences in juvenile mouse social behavior are influenced by sex chromosomes and social context. Genes Brain Behav. 10 (4), 465-472.

Crain, J.M., Nikodemova, M., Watters, J.J., 2013. Microglia express distinct M1 and M2 phenotypic markers in the postnatal and adult central nervous system in male and female mice. J Neurosci Res. 91 (9), 1143-1151. 
Critchlow, V., Liebelt, R.A., Bar-Sela, M., Mountcastle, W., Lipscomb, H.S., 1963. Sex difference in resting pituitary-adrenal function in the rat. Am J Physiol. 205 (5), 807-815.

Csankovszki, G., Nagy, A., Jaenisch, R., 2001. Synergism of Xist RNA, DNA methylation, and histone hypoacetylation in maintaining X chromosome inactivation. J Cell Biol. 153 (4), 773-784.

Curtis, A.L., Bethea, T., Valentino, R.J., 2006. Sexually dimorphic responses of the brain norepinephrine system to stress and corticotropin-releasing factor. Neuropsychopharmacol. 31 (3), 544-554.

Davies, W., Isles, A.R., Burgoyne, P.S., Wilkinson, L.S., 2006. X-linked imprinting: effects on brain and behaviour. Bioessays. 28 (1), 35-44.

Davis, E.C., Popper, P., Gorski, R.A., 1996. The role of apoptosis in sexual differentiation of the rat sexually dimorphic nucleus of the preoptic area. Brain Res. 734 (1-2), 10-18.

De Vries, G.J., 2004. Minireview: Sex differences in adult and developing brains: compensation, compensation, compensation. Endocrinology. 145 (3), 1063-1068.

De Vries, G.J., Forger, N.G., 2015. Sex differences in the brain: a whole body perspective. Biol Sex Differ. 6, 15.

De Vries, G.J., Jardon, M., Reza, M., Rosen, G.J., Immerman, E., Forger, N.G., 2008. Sexual differentiation of vasopressin innervation of the brain: cell death versus phenotypic differentiation. Endocrinology. 149 (9), 4632-4637.

De Vries, G.J., Panzica, G.C., 2006. Sexual differentiation of central vasopressin and vasotocin systems in vertebrates: different mechanisms, similar endpoints. Neuroscience. 138 (3), 947955. 
De Vries, G.J., Rissman, E.F., Simerly, R.B., Yang, L.Y., Scordalakes, E.M., Auger, C.J., Swain, A., Lovell-Badge, R., Burgoyne, P.S., Arnold, A.P., 2002. A model system for study of sex chromosome effects on sexually dimorphic neural and behavioral traits. J Neurosci. 22 (20), 9005-9014.

Del Pino Sans, J., Krishnan, S., Aggison, L.K., Adams, H.L., Shrikant, M.M., Lopez-Giraldez, F., Petersen, S.L., 2015. Microarray analysis of neonatal rat anteroventral periventricular transcriptomes identifies the proapoptotic Cugbp2 gene as sex-specific and regulated by estradiol. Neuroscience. 303, 312-322.

Dewing, P., Chiang, C.W., Sinchak, K., Sim, H., Fernagut, P.O., Kelly, S., Chesselet, M.F., Micevych, P.E., Albrecht, K.H., Harley, V.R., Vilain, E., 2006. Direct regulation of adult brain function by the male-specific factor SRY. Curr Biol. 16 (4), 415-420.

DiBlasio, C.J., Hammett, J., Malcolm, J.B., Judge, B.A., Womack, J.H., Kincade, M.C., Ogles, M.L., Mancini, J.G., Patterson, A.L., Wake, R.W., Derweesh, I.H., 2008. Prevalence and predictive factors for the development of de novo psychiatric illness in patients receiving androgen deprivation therapy for prostate cancer. Can J Urol. 15 (5), 4249-4256.

DonCarlos, L.L., 1996. Developmental profile and regulation of estrogen receptor (ER) mRNA expression in the preoptic area of prenatal rats. Brain Res Dev Brain Res. 94 (2), 224-233.

Du, S., Itoh, N., Askarinam, S., Hill, H., Arnold, A.P., Voskuhl, R.R., 2014. XY sex chromosome complement, compared with XX, in the CNS confers greater neurodegeneration during experimental autoimmune encephalomyelitis. Proc Natl Acad Sci U S A. 111 (7), 2806-2811.

Duncko, R., Kiss, A., Skultetyova, I., Rusnak, M., Jezova, D., 2001. Corticotropin-releasing hormone mRNA levels in response to chronic mild stress rise in male but not in female rats 
while tyrosine hydroxylase mRNA levels decrease in both sexes. Psychoneuroendocrino. 26 (1), 77-89.

Edelmann, M., Wolfe, C., Scordalakes, E.M., Rissman, E.F., Tobet, S., 2007. Neuronal nitric oxide synthase and calbindin delineate sex differences in the developing hypothalamus and preoptic area. Dev Neurobiol. 67 (10), 1371-1381.

Edelmann, M.N., Auger, A.P., 2011. Epigenetic impact of simulated maternal grooming on estrogen receptor alpha within the developing amygdala. Brain Behav Immun. 25 (7), 12991304.

Fishman, R.B., Breedlove, S.M., 1992. Local perineal implants of anti-androgen block masculinization of the spinal nucleus of the bulbocavernosus. Brain Res Dev Brain Res. 70 (2), 283-286.

Fishman, R.B., Chism, L., Firestone, G.L., Breedlove, S.M., 1990. Evidence for androgen receptors in sexually dimorphic perineal muscles of neonatal male rats. Absence of androgen accumulation by the perineal motoneurons. J Neurobiol. 21 (5), 694-704.

Forger, N.G., 2006. Cell death and sexual differentiation of the nervous system. Neuroscience. $138(3), 929-938$.

Forger, N.G., 2009. The organizational hypothesis and final common pathways: Sexual differentiation of the spinal cord and peripheral nervous system. Horm Behav. 55 (5), 605-610.

Forger, N.G., 2016. Epigenetic mechanisms of sexual differentiation of the brain and behavior. Philos T Roy Soc B. [Submitted].

Forger, N.G., Breedlove, S.M., 1986. Sexual dimorphism in human and canine spinal cord: role of early androgen. Proc Natl Acad Sci U S A. 83 (19), 7527-7531. 
Forger, N.G., Breedlove, S.M., 1987. Seasonal variation in mammalian striated muscle mass and motoneuron morphology. J Neurobiol. 18 (2), 155-165.

Forger, N.G., De Vries, G.J., Breedlove, S.M. 2015. Sexual differentiation of brain and behavior. In: T.M. Plant, and A.J. Zeleznik (Eds). Knobil and Neill's Physiology of Reproduction. Fourth Edition.Elsevier, Amsterdam. pp. 2109-2155.

Forger, N.G., Roberts, S.L., Wong, V., Breedlove, S.M., 1993. Ciliary neurotrophic factor maintains motoneurons and their target muscles in developing rats. J Neurosci. 13 (11), 47204726.

Forger, N.G., Rosen, G.J., Waters, E.M., Jacob, D., Simerly, R.B., de Vries, G.J., 2004. Deletion of Bax eliminates sex differences in the mouse forebrain. Proc Natl Acad Sci U S A. 101 (37), 13666-13671.

Forger, N.G., Wong, V., Breedlove, S.M., 1995. Ciliary neurotrophic factor arrests muscle and motoneuron degeneration in androgen-insensitive rats. J Neurobiol. 28 (3), 354-362.

Foster, J.A., McVey Neufeld, K.A., 2013. Gut-brain axis: how the microbiome influences anxiety and depression. Trends Neurosci. 36 (5), 305-312.

Francisco, F.O., Lemos, B., 2014. How do y-chromosomes modulate genome-wide epigenetic States: genome folding, chromatin sinks, and gene expression. J Genomics. 2, 94-103.

Freeman, L.M., Watson, N.V., Breedlove, S.M., 1996. Androgen spares androgen-insensitive motoneurons from apoptosis in the spinal nucleus of the bulbocavernosus in rats. Horm Behav. 30 (4), 424-433. 
Gatewood, J.D., Wills, A., Shetty, S., Xu, J., Arnold, A.P., Burgoyne, P.S., Rissman, E.F., 2006. Sex chromosome complement and gonadal sex influence aggressive and parental behaviors in mice. J Neurosci. 26 (8), 2335-2342.

Ghahramani, N.M., Ngun, T.C., Chen, P.Y., Tian, Y., Krishnan, S., Muir, S., Rubbi, L., Arnold, A.P., de Vries, G.J., Forger, N.G., Pellegrini, M., Vilain, E., 2014. The effects of perinatal testosterone exposure on the DNA methylome of the mouse brain are late-emerging. Biol Sex Differ. 5, 8.

Gilmore, R.F., Varnum, M.M., Forger, N.G., 2012. Effects of blocking developmental cell death on sexually dimorphic calbindin cell groups in the preoptic area and bed nucleus of the stria terminalis. Biol Sex Differ. 3, 5.

Gioiosa, L., Chen, X., Watkins, R., Klanfer, N., Bryant, C.D., Evans, C.J., Arnold, A.P., 2008. Sex chromosome complement affects nociception in tests of acute and chronic exposure to morphine in mice. Horm Behav. 53 (1), 124-130.

Goel, N., Bale, T.L., 2010. Sex differences in the serotonergic influence on the hypothalamicpituitary-adrenal stress axis. Endocrinology. 151 (4), 1784-1794.

Gold, P.W., Chrousos, G.P., 2002. Organization of the stress system and its dysregulation in melancholic and atypical depression: high vs low $\mathrm{CRH} / \mathrm{NE}$ states. Mol Psychiatry. 7 (3), 254275.

Gonzalez-Martinez, D., De Mees, C., Douhard, Q., Szpirer, C., Bakker, J., 2008. Absence of gonadotropin-releasing hormone 1 and Kiss 1 activation in alpha-fetoprotein knockout mice: prenatal estrogens defeminize the potential to show preovulatory luteinizing hormone surges. Endocrinology. 149 (5), 2333-2340. 
Gotsiridze, T., Kang, N., Jacob, D., Forger, N.G., 2007. Development of sex differences in the principal nucleus of the bed nucleus of the stria terminalis of mice: role of Bax-dependent cell death. Dev Neurobiol. 67 (3), 355-362.

Greer, G.R., Grob, C.S., Halberstadt, A.L., 2014. PTSD symptom reports of patients evaluated for the New Mexico Medical Cannabis Program. J Psychoactive Drugs. 46 (1), 73-77.

Griffin, G.D., Flanagan-Cato, L.M., 2009. Sex differences in the dendritic arbor of hypothalamic ventromedial nucleus neurons. Physiol Behav. 97 (2), 151-156.

Handa, R.J., Burgess, L.H., Kerr, J.E., O'Keefe, J.A., 1994. Gonadal steroid hormone receptors and sex differences in the hypothalamo-pituitary-adrenal axis. Horm Behav. 28 (4), 464-476.

Hebbeler, S.L., Verhovshek, T., Sengelaub, D.R., 2002. N-methyl-D-aspartate receptor blockade inhibits estrogenic support of dendritic growth in a sexually dimorphic rat spinal nucleus. J Comp Neurol. 451 (2), 142-152.

Henderson, R.G., Brown, A.E., Tobet, S.A., 1999. Sex differences in cell migration in the preoptic area/anterior hypothalamus of mice. J Neurobiol. 41 (2), 252-266.

Herbison, A.E., 2008. Estrogen positive feedback to gonadotropin-releasing hormone $(\mathrm{GnRH})$ neurons in the rodent: the case for the rostral periventricular area of the third ventricle (RP3V). Brain Res Rev. 57 (2), 277-287.

Hill, M.N., Patel, S., 2013. Translational evidence for the involvement of the endocannabinoid system in stress-related psychiatric illnesses. Biol Mood Anxiety Disord. 3 (1), 19.

Hisasue, S.-i., Seney, M.L., Immerman, E., Forger, N.G., 2010. Control of cell number in the bed nucleus of the stria terminalis of mice: role of testosterone metabolites and estrogen receptor subtypes. J Sex Med. 7, 1401-1409. 
Holmes, M.M., Goldman, B.D., Goldman, S.L., Seney, M.L., Forger, N.G., 2009.

Neuroendocrinology and sexual differentiation in eusocial mammals. Front Neuroendocrinol. 30 (4), 519-533.

Hong, S., Cho, Y.W., Yu, L.R., Yu, H., Veenstra, T.D., Ge, K., 2007. Identification of JmjC domain-containing UTX and JMJD3 as histone H3 lysine 27 demethylases. Proc Natl Acad Sci U S A. 104 (47), 18439-18444.

Huang, G.Z., Woolley, C.S., 2012. Estradiol acutely suppresses inhibition in the hippocampus through a sex-specific endocannabinoid and mGluR-dependent mechanism. Neuron. 74 (5), 801-808.

Ikeda, Y., Luo, X., Abbud, R., Nilson, J.H., Parker, K.L., 1995. The nuclear receptor steroidogenic factor 1 is essential for the formation of the ventromedial hypothalamic nucleus. Mol Endocrinol. 9 (4), 478-486.

Imwalle, D.B., Bateman, H.L., Wills, A., Honda, S., Harada, N., Rissman, E.F., 2006. Impairment of spatial learning by estradiol treatment in female mice is attenuated by estradiol exposure during development. Horm Behav. 50 (5), 693-698.

Iwase, S., Lan, F., Bayliss, P., de la Torre-Ubieta, L., Huarte, M., Qi, H.H., Whetstine, J.R., Bonni, A., Roberts, T.M., Shi, Y., 2007. The X-linked mental retardation gene SMCX/JARID1C defines a family of histone H3 lysine 4 demethylases. Cell. 128 (6), 1077-1088.

Jacob, D.A., Bengston, C.L., Forger, N.G., 2005. Effects of Bax gene deletion on muscle and motoneuron degeneration in a sexually dimorphic neuromuscular system. J Neurosci. 25 (23), $5638-5644$. 
Jedema, H.P., Grace, A.A., 2004. Corticotropin-releasing hormone directly activates noradrenergic neurons of the locus ceruleus recorded in vitro. J Neurosci. 24 (43), 9703-9713.

Jo, Y.H., Stoeckel, M.E., Freund-Mercier, M.J., Schlichter, R., 1998. Oxytocin modulates glutamatergic synaptic transmission between cultured neonatal spinal cord dorsal horn neurons. J Neurosci. 18 (7), 2377-2386.

Johnson, R.T., Breedlove, S.M., Jordan, C.L., 2008. Sex differences and laterality in astrocyte number and complexity in the adult rat medial amygdala. J Comp Neurol. 511 (5), 599-609.

Jordan, C.L., Breedlove, S.M., Arnold, A.P., 1991. Ontogeny of steroid accumulation in spinal lumbar motoneurons of the rat: implications for androgen's site of action during synapse elimination. J Comp Neurol. 313 (3), 441-448.

Jordan, C.L., Padgett, B., Hershey, J., Prins, G., Arnold, A., 1997. Ontogeny of androgen receptor immunoreactivity in lumbar motoneurons and in the sexually dimorphic levator ani muscle of male rats. J Comp Neurol. 379 (1), 88-98.

Kashimada, K., Koopman, P., 2010. Sry: the master switch in mammalian sex determination. Development. 137 (23), 3921-3930.

Kato, Y., Nakashima, S., Maekawa, F., Tsukahara, S., 2012. Involvement of postnatal apoptosis on sex difference in number of cells generated during late fetal period in the sexually dimorphic nucleus of the preoptic area in rats. Neurosci Lett. 516 (2), 290-295.

Kauffman, A.S., Gottsch, M.L., Roa, J., Byquist, A.C., Crown, A., Clifton, D.K., Hoffman, G.E., Steiner, R.A., Tena-Sempere, M., 2007. Sexual differentiation of Kiss1 gene expression in the brain of the rat. Endocrinology. 148 (4), 1774-1783. 
Kelly, D.A., Varnum, M.M., Krentzel, A.A., Krug, S., Forger, N.G., 2013. Differential control of sex differences in estrogen receptor $\alpha$ in the bed nucleus of the stria terminalis and anteroventral periventricular nucleus. Endocrinology. 154 (10), 3836-3846.

Kessler, R.C., 2003. Epidemiology of women and depression. J Affect Disord. 74 (1), 5-13.

Khalil, A.M., Driscoll, D.J., 2007. Trimethylation of histone H3 lysine 4 is an epigenetic mark at regions escaping mammalian $\mathrm{X}$ inactivation. Epigenetics. 2 (2), 114-118.

Kim, S., Voskuhl, R.R., 1999. Decreased IL-12 production underlies the decreased ability of male lymph node cells to induce experimental autoimmune encephalomyelitis. J Immunol. 162 (9), 5561-5568.

Kimura, D., 2002. Sex hormones influence human cognitive pattern. Neuro Endocrinol Lett. 23 Suppl 4, 67-77.

Kininis, M., Chen, B.S., Diehl, A.G., Isaacs, G.D., Zhang, T., Siepel, A.C., Clark, A.G., Kraus, W.L., 2007. Genomic analyses of transcription factor binding, histone acetylation, and gene expression reveal mechanistically distinct classes of estrogen-regulated promoters. Mol Cell Biol. 27 (14), 5090-5104.

Kishimoto, M., Fujiki, R., Takezawa, S., Sasaki, Y., Nakamura, T., Yamaoka, K., Kitagawa, H., Kato, S., 2006. Nuclear receptor mediated gene regulation through chromatin remodeling and histone modifications. Endocr J. 53 (2), 157-172.

Kitay, J.I., 1961. Sex differences in adrenal cortical secretion in the rat. Endocrinology. 68, 818824.

Knoll, J.G., Wolfe, C.A., Tobet, S.A., 2007. Estrogen modulates neuronal movements within the developing preoptic area-anterior hypothalamus. Eur J Neurosci. 26 (5), 1091-1099. 
Konkle, A.T., McCarthy, M.M., 2011. Developmental time course of estradiol, testosterone, and dihydrotestosterone levels in discrete regions of male and female rat brain. Endocrinology. 152 (1), 223-235.

Koob, G.F., 1999. Corticotropin-releasing factor, norepinephrine, and stress. Biol Psychiatry. 46 (9), 1167-1180.

Koopman, P., Gubbay, J., Vivian, N., Goodfellow, P., Lovell-Badge, R., 1991. Male development of chromosomally female mice transgenic for Sry. Nature. 351 (6322), 117-121.

Krentzel, A.A., Remage-Healey, L., 2015. Sex differences and rapid estrogen signaling: A look at songbird audition. Front Neuroendocrinol. 38, 37-49.

Krishnan, S., Intlekofer, K.A., Aggison, L.K., Petersen, S.L., 2009. Central role of TRAFinteracting protein in a new model of brain sexual differentiation. Proc Natl Acad Sci U S A. 106 (39), 16692-16697.

Kroemer, G., Martin, S.J., 2005. Caspase-independent cell death. Nat Med. 11 (7), 725-730.

Kuan, C.Y., Roth, K.A., Flavell, R.A., Rakic, P., 2000. Mechanisms of programmed cell death in the developing brain. Trends Neurosci. 23 (7), 291-297.

Kurian, J.R., Olesen, K.M., Auger, A.P., 2010. Sex differences in epigenetic regulation of the estrogen receptor-alpha promoter within the developing preoptic area. Endocrinology. 151 (5), 2297-2305.

Kurz, E.M., Sengelaub, D.R., Arnold, A.P., 1986. Androgens regulate the dendritic length of mammalian motoneurons in adulthood. Science. 232 (4748), 395-398. 
Lenz, K.M., McCarthy, M.M., 2015. A starring role for microglia in brain sex differences. Neuroscientist. 21 (3), 306-321.

Lenz, K.M., Nugent, B.M., Haliyur, R., McCarthy, M.M., 2013. Microglia are essential to masculinization of brain and behavior. J Neurosci. 33 (7), 2761-2772.

Lenz, K.M., Sengelaub, D.R., 2006. Maternal licking influences dendritic development of motoneurons in a sexually dimorphic neuromuscular system. Brain Res. 1092 (1), 87-99.

Lenz, K.M., Sengelaub, D.R., 2010. Maternal care effects on the development of a sexually dimorphic motor system: the role of spinal oxytocin. Horm Behav. 58 (4), 575-581.

Lenz, K.M., Wright, C.L., Martin, R.C., McCarthy, M.M., 2011. Prostaglandin E(2) regulates AMPA receptor phosphorylation and promotes membrane insertion in preoptic area neurons and glia during sexual differentiation. PLoS One. 6 (4), e18500.

Loram, L.C., Sholar, P.W., Taylor, F.R., Wiesler, J.L., Babb, J.A., Strand, K.A., Berkelhammer, D., Day, H.E., Maier, S.F., Watkins, L.R., 2012. Sex and estradiol influence glial proinflammatory responses to lipopolysaccharide in rats. Psychoneuroendocrino. 37 (10), 16881699.

Louveau, A., Smirnov, I., Keyes, T.J., Eccles, J.D., Rouhani, S.J., Peske, J.D., Derecki, N.C., Castle, D., Mandell, J.W., Lee, K.S., Harris, T.H., Kipnis, J., 2015. Structural and functional features of central nervous system lymphatic vessels. Nature. 523 (7560), 337-341.

Luttrell, L.M., Lefkowitz, R.J., 2002. The role of beta-arrestins in the termination and transduction of G-protein-coupled receptor signals. J Cell Sci. 115 (Pt 3), 455-465. 
Madeira, M.D., Ferreira-Silva, L., Paula-Barbosa, M.M., 2001. Influence of sex and estrus cycle on the sexual dimorphisms of the hypothalamic ventromedial nucleus: stereological evaluation and Golgi study. J Comp Neurol. 432 (3), 329-345.

Majdic, G., Tobet, S., 2011. Cooperation of sex chromosomal genes and endocrine influences for hypothalamic sexual differentiation. Front Neuroendocrinol. 32 (2), 137-145.

Markle, J.G., Frank, D.N., Mortin-Toth, S., Robertson, C.E., Feazel, L.M., Rolle-Kampczyk, U., von Bergen, M., McCoy, K.D., Macpherson, A.J., Danska, J.S., 2013. Sex differences in the gut microbiome drive hormone-dependent regulation of autoimmunity. Science. 339 (6123), 10841088.

Matsuda, K.I., Mori, H., Nugent, B.M., Pfaff, D.W., McCarthy, M.M., Kawata, M., 2011. Histone deacetylation during brain development is essential for permanent masculinization of sexual behavior. Endocrinology. 152 (7), 2760-2767.

Mauvais-Jarvis, F., 2015. Sex differences in metabolic homeostasis, diabetes, and obesity. Biol Sex Differ. 6, 14.

McCarthy, M.M., 2011. A lumpers versus splitters approach to sexual differentiation of the brain. Front Neuroendocrinol. 32 (2), 114-123.

McCarthy, M.M., Nugent, B.M., 2013. Epigenetic contributions to hormonally-mediated sexual differentiation of the brain. J Neuroendocrinol. 25 (11), 1133-1140.

McCarthy, M.M., Pickett, L.A., VanRyzin, J.W., Kight, K.E., 2015. Surprising origins of sex differences in the brain. Horm Behav. [Epub ahead of print]. 
McCarthy, M.M., Wright, C.L., Schwarz, J.M., 2009. New tricks by an old dogma: mechanisms of the Organizational/Activational Hypothesis of steroid-mediated sexual differentiation of brain and behavior. Horm Behav. 55 (5), 655-665.

McEwen, B.S., Plapinger, L., Chaptal, C., Gerlach, J., Wallach, G., 1975. Role of fetoneonatal estrogen binding proteins in the associations of estrogen with neonatal brain cell nuclear receptors. Brain Res. 96 (2), 400-406.

Mechakra-Tahiri, S.D., Zunzunegui, M.V., Preville, M., Dube, M., 2010. Gender, social relationships and depressive disorders in adults aged 65 and over in Quebec. Chronic Dis Can. $30(2), 56-65$.

Merali, Z., Du, L., Hrdina, P., Palkovits, M., Faludi, G., Poulter, M.O., Anisman, H., 2004. Dysregulation in the suicide brain: mRNA expression of corticotropin-releasing hormone receptors and $\operatorname{GABA}(A)$ receptor subunits in frontal cortical brain region. J Neurosci. 24 (6), $1478-1485$.

Micevych, P., Sinchak, K., 2011. The neurosteroid progesterone underlies estrogen positive feedback of the LH surge. Front Endocrinol. 2, 90.

Miller, K.K., Perlis, R.H., Papakostas, G.I., Mischoulon, D., Losifescu, D.V., Brick, D.J., Fava, M., 2009. Low-dose transdermal testosterone augmentation therapy improves depression severity in women. CNS Spectr. 14 (12), 688-694.

Mirandola, L., Wade, R., Verma, R., Pena, C., Hosiriluck, N., Figueroa, J.A., Cobos, E., Jenkins, M.R., Chiriva-Internati, M., 2015. Sex-driven differences in immunological responses: challenges and opportunities for the immunotherapies of the third millennium. Int Rev Immunol. $34(2), 134-142$. 
Mong, J.A., Kurzweil, R.L., Davis, A.M., Rocca, M.S., McCarthy, M.M., 1996. Evidence for sexual differentiation of glia in rat brain. Horm Behav. 30 (4), 553-562.

Mong, J.A., McCarthy, M.M., 1999. Steroid-induced developmental plasticity in hypothalamic astrocytes: implications for synaptic patterning. J Neurobiol. 40 (4), 602-619.

Mong, J.A., McCarthy, M.M., 2002. Ontogeny of sexually dimorphic astrocytes in the neonatal rat arcuate. Brain Res Dev Brain Res. 139 (2), 151-158.

Mong, J.A., Nunez, J.L., McCarthy, M.M., 2002. GABA mediates steroid-induced astrocyte differentiation in the neonatal rat hypothalamus. J Neuroendocrinol. 14 (1), 45-55.

Moore, C.L., 1985. Sex differences in urinary odors produced by young laboratory rats (Rattus norvegicus). J Comp Psychol. 99 (3), 336-341.

Moore, C.L., Dou, H., Juraska, J.M., 1992. Maternal stimulation affects the number of motor neurons in a sexually dimorphic nucleus of the lumbar spinal cord. Brain Res. 572 (1-2), 52-56.

Murray, E.K., Hien, A., de Vries, G.J., Forger, N.G., 2009. Epigenetic control of sexual differentiation of the bed nucleus of the stria terminalis. Endocrinology. 150 (9), 4241-4247.

Naftolin, F., 1994. Brain aromatization of androgens. J Reprod Med. 39 (4), 257-261.

Negri-Cesi, P., Colciago, A., Motta, M., Martini, L., Celotti, F., 2001. Aromatase expression and activity in male and female cultured rat hypothalamic neurons: effect of androgens. Mol Cell Endocrinol. 178 (1-2), 1-10.

Nemeroff, C.B., Widerlov, E., Bissette, G., Walleus, H., Karlsson, I., Eklund, K., Kilts, C.D., Loosen, P.T., Vale, W., 1984. Elevated concentrations of CSF corticotropin-releasing factor-like immunoreactivity in depressed patients. Science. 226 (4680), 1342-1344. 
Niel, L., Willemsen, K.R., Volante, S.N., Monks, D.A., 2008. Sexual dimorphism and androgen regulation of satellite cell population in differentiating rat levator ani muscle. Dev Neurobiol. 68 (1), 115-122.

Ninkovic, J., Gotz, M., 2013. Fate specification in the adult brain--lessons for eliciting neurogenesis from glial cells. Bioessays. 35 (3), 242-252.

Nordeen, E.J., Nordeen, K.W., Sengelaub, D.R., Arnold, A.P., 1985. Androgens prevent normally occurring cell death in a sexually dimorphic spinal nucleus. Science. 229 (4714), 671673.

Nugent, B.M., Wright, C.L., Shetty, A.C., Hodes, G.E., Lenz, K.M., Mahurkar, A., Russo, S.J., Devine, S.E., McCarthy, M.M., 2015. Brain feminization requires active repression of masculinization via DNA methylation. Nat Neurosci. 18 (5), 690-697.

Oomen, C.A., Girardi, C.E., Cahyadi, R., Verbeek, E.C., Krugers, H., Joels, M., Lucassen, P.J., 2009. Opposite effects of early maternal deprivation on neurogenesis in male versus female rats. PLoS One. 4 (1), e3675.

Oppenheim, R.W., 1985. Cyclic GMP and neurone death. Nature. 313 (5999), 248.

Orikasa, C., Kondo, Y., Hayashi, S., McEwen, B.S., Sakuma, Y., 2002. Sexually dimorphic expression of estrogen receptor beta in the anteroventral periventricular nucleus of the rat preoptic area: implication in luteinizing hormone surge. Proc Natl Acad Sci U S A. 99 (5), 33063311.

Orikasa, C., Sakuma, Y., 2010. Estrogen configures sexual dimorphism in the preoptic area of C57BL/6J and ddN strains of mice. J Comp Neurol. 518 (17), 3618-3629. 
Peters, N.V., Paul, M.J., Chassaing, B., Gewirtz, A.T., De Vries, G.J., 2015. Microbiota impact vasopressin immunoreactivity in adult swiss-webster mice in a sex-dependent manner. Poster No. P3.07. Society for Behavioral Neuroendocrinology 19th Annual Meeting. Pacific Grove, CA.

Phoenix, C.H., Goy, R.W., Gerall, A.A., Young, W.C., 1959. Organizing action of prenatally administered testosterone propionate on the tissues mediating mating behavior in the female guinea pig. Endocrinology. 65, 369-382.

Planas, B., Kolb, P.E., Raskind, M.A., Miller, M.A., 1995. Sex difference in coexpression by galanin neurons accounts for sexual dimorphism of vasopressin in the bed nucleus of the stria terminalis. Endocrinology. 136 (2), 727-733.

Rand, M.N., Breedlove, S.M., 1995. Androgen alters the dendritic arbors of SNB motoneurons by acting upon their target muscles. J Neurosci. 15 (6), 4408-4416.

Ransohoff, R.M., Brown, M.A., 2012. Innate immunity in the central nervous system. J Clin Invest. 122 (4), 1164-1171.

Resko, J.A. 1985. Gonadal hormones during sexual differentiation in vertebrates. In: N. Adler, D. Pfaff, and R. Goy (Eds). Handbook of Behavioral Neurobiology. Plenum Press, New York, NY. pp. 21-42.

Reyes, B.A., Fox, K., Valentino, R.J., Van Bockstaele, E.J., 2006. Agonist-induced internalization of corticotropin-releasing factor receptors in noradrenergic neurons of the rat locus coeruleus. Eur J Neurosci. 23 (11), 2991-2998.

Reyes, B.A., Valentino, R.J., Xu, G., Van Bockstaele, E.J., 2005. Hypothalamic projections to locus coeruleus neurons in rat brain. Eur J Neurosci. 22 (1), 93-106. 
Reyes, F.I., Boroditsky, R.S., Winter, J.S., Faiman, C., 1974. Studies on human sexual development. II. Fetal and maternal serum gonadotropin and sex steroid concentrations. J Clin Endocrinol Metab. 38 (4), 612-617.

Ridlon, J.M., Ikegawa, S., Alves, J.M., Zhou, B., Kobayashi, A., lida, T., Mitamura, K., Tanabe, G., Serrano, M., De Guzman, A., Cooper, P., Buck, G.A., Hylemon, P.B., 2013. Clostridium scindens: a human gut microbe with a high potential to convert glucocorticoids into androgens. J Lipid Res. 54 (9), 2437-2449.

Robel, P., Baulieu, E.E., 1995. Neurosteroids: biosynthesis and function. Crit Rev Neurobiol. 9 (4), 383-394.

Roselli, C.E., Liu, M., Hurn, P.D., 2009. Brain aromatization: classic roles and new perspectives. Semin Reprod Med. 27 (3), 207-217.

Roth, K.A., D'Sa, C., 2001. Apoptosis and brain development. Ment Retard Dev Disabil Res Rev. 7 (4), 261-266.

Santos-Galindo, M., Acaz-Fonseca, E., Bellini, M.J., Garcia-Segura, L.M., 2011. Sex differences in the inflammatory response of primary astrocytes to lipopolysaccharide. Biol Sex Differ. 2, 7.

Schwarz, J.M., Liang, S.L., Thompson, S.M., McCarthy, M.M., 2008. Estradiol induces hypothalamic dendritic spines by enhancing glutamate release: a mechanism for organizational sex differences. Neuron. 58 (4), 584-598.

Schwarz, J.M., Nugent, B.M., McCarthy, M.M., 2010. Developmental and hormone-induced epigenetic changes to estrogen and progesterone receptor genes in brain are dynamic across the life span. Endocrinology. 151 (10), 4871-4881. 
Schwarz, J.M., Sholar, P.W., Bilbo, S.D., 2012. Sex differences in microglial colonization of the developing rat brain. J Neurochem. 120 (6), 948-963.

Sechzer, J.A., Rabinowitz, V.C., Denmark, F.L., McGinn, M.F., Weeks, B.M., Wilkens, C.L., 1994. Sex and gender bias in animal research and in clinical studies of cancer, cardiovascular disease, and depression. Ann N Y Acad Sci. 736, 21-48.

Semaan, S.J., Murray, E.K., Poling, M.C., Dhamija, S., Forger, N.G., Kauffman, A.S., 2010. BAX-dependent and BAX-independent regulation of Kiss1 neuron development in mice. Endocrinology. 151 (12), 5807-5817.

Semont, A., Fache, M., Hery, F., Faudon, M., Youssouf, F., Hery, M., 2000. Regulation of central corticosteroid receptors following short-term activation of serotonin transmission by 5hydroxy-L-tryptophan or fluoxetine. J Neuroendocrinol. 12 (8), 736-744.

Seney, M.L., Ekong, K.I., Ding, Y., Tseng, G.C., Sibille, E., 2013. Sex chromosome complement regulates expression of mood-related genes. Biol Sex Differ. 4 (1), 20.

Sengelaub, D.R., Forger, N.G., 2008. The spinal nucleus of the bulbocavernosus: firsts in androgen-dependent neural sex differences. Horm Behav. 53 (5), 596-612.

Shen, E.Y., Ahern, T.H., Cheung, I., Straubhaar, J., Dincer, A., Houston, I., de Vries, G.J., Akbarian, S., Forger, N.G., 2015. Epigenetics and sex differences in the brain: A genome-wide comparison of histone-3 lysine-4 trimethylation (H3K4me3) in male and female mice. Exp Neurol. 268, 21-29.

Shinoda, K., Lei, H., Yoshii, H., Nomura, M., Nagano, M., Shiba, H., Sasaki, H., Osawa, Y., Ninomiya, Y., Niwa, O., et al., 1995. Developmental defects of the ventromedial hypothalamic nucleus and pituitary gonadotroph in the Ftz-F1 disrupted mice. Dev Dyn. 204 (1), 22-29. 
Shors, T.J., Chua, C., Falduto, J., 2001. Sex differences and opposite effects of stress on dendritic spine density in the male versus female hippocampus. J Neurosci. 21 (16), 6292-6297.

Simerly, R.B., Swanson, L.W., Handa, R.J., Gorski, R.A., 1985. Influence of perinatal androgen on the sexually dimorphic distribution of tyrosine hydroxylase-immunoreactive cells and fibers in the anteroventral periventricular nucleus of the rat. Neuroendocrinology. 40 (6), 501-510.

Smith-Bouvier, D.L., Divekar, A.A., Sasidhar, M., Du, S., Tiwari-Woodruff, S.K., King, J.K., Arnold, A.P., Singh, R.R., Voskuhl, R.R., 2008. A role for sex chromosome complement in the female bias in autoimmune disease. J Exp Med. 205 (5), 1099-1108.

Sonnenberg, C.M., Beekman, A.T., Deeg, D.J., van Tilburg, W., 2000. Sex differences in latelife depression. Acta Psychiatr Scand. 101 (4), 286-292.

Sorge, R.E., LaCroix-Fralish, M.L., Tuttle, A.H., Sotocinal, S.G., Austin, J.S., Ritchie, J., Chanda, M.L., Graham, A.C., Topham, L., Beggs, S., Salter, M.W., Mogil, J.S., 2011. Spinal cord Toll-like receptor 4 mediates inflammatory and neuropathic hypersensitivity in male but not female mice. J Neurosci. 31 (43), 15450-15454.

Sorge, R.E., Mapplebeck, J.C., Rosen, S., Beggs, S., Taves, S., Alexander, J.K., Martin, L.J., Austin, J.S., Sotocinal, S.G., Chen, D., Yang, M., Shi, X.Q., Huang, H., Pillon, N.J., Bilan, P.J., Tu, Y., Klip, A., Ji, R.R., Zhang, J., Salter, M.W., Mogil, J.S., 2015. Different immune cells mediate mechanical pain hypersensitivity in male and female mice. Nat Neurosci. 18 (8), 1081 1083.

Southwick, S.M., Bremner, J.D., Rasmusson, A., Morgan, C.A., Brd, Arnsten, A., Charney, D.S., 1999. Role of norepinephrine in the pathophysiology and treatment of posttraumatic stress disorder. Biol Psychiatry. 46 (9), 1192-1204. 
Spence, R.D., Voskuhl, R.R., 2012. Neuroprotective effects of estrogens and androgens in CNS inflammation and neurodegeneration. Front Neuroendocrinol. 33 (1), 105-115.

Spencer, T.E., Jenster, G., Burcin, M.M., Allis, C.D., Zhou, J., Mizzen, C.A., McKenna, N.J., Onate, S.A., Tsai, S.Y., Tsai, M.J., O'Malley, B.W., 1997. Steroid receptor coactivator-1 is a histone acetyltransferase. Nature. 389 (6647), 194-198.

Sterrenburg, L., Gaszner, B., Boerrigter, J., Santbergen, L., Bramini, M., Elliott, E., Chen, A., Peeters, B.W., Roubos, E.W., Kozicz, T., 2011. Chronic stress induces sex-specific alterations in methylation and expression of corticotropin-releasing factor gene in the rat. PLoS One. 6 (11), e28128.

Suárez, I., Bodega, G., Rubio, M., Fernández, B., 1992. Sexual dimorphism in the hamster cerebellum demonstrated by glial fibrillary acidic protein (GFAP) and vimentin immunoreactivity. Glia. 5 (1), 10-16.

Swift-Gallant, A., Monks, D.A., 2013. Androgen receptor expression in satellite cells of the neonatal levator ani of the rat. Dev Neurobiol. 73 (6), 448-454.

Tabatadze, N., Huang, G., May, R.M., Jain, A., Woolley, C.S., 2015. Sex Differences in Molecular Signaling at Inhibitory Synapses in the Hippocampus. J Neurosci. 35 (32), 1125211265.

Tetel, M.J., 2009. Nuclear receptor coactivators: essential players for steroid hormone action in the brain and in behaviour. J Neuroendocrinol. 21 (4), 229-237.

Thornton, J., Zehr, J.L., Loose, M.D., 2009. Effects of prenatal androgens on rhesus monkeys: a model system to explore the organizational hypothesis in primates. Horm Behav. 55 (5), 633645. 
Tonelli, L.H., Holmes, A., Postolache, T.T., 2008. Intranasal immune challenge induces sexdependent depressive-like behavior and cytokine expression in the brain.

Neuropsychopharmacology. 33 (5), 1038-1048.

Toran-Allerand, C.D. 1984. On the genesis of sexual differentiation of the central nervous system: morphogenetic consequences of steroidal exposure and possible role of a-fetoprotein. In: G.J. De Vries, J.P.C. De Bruin, H.B.M. Uylings, and M.A. Corner (Eds). Sex Differences in the Brain: The Relation between Structure and FunctionElsevier, Amsterdam. pp. 63-98.

Town, T., Nikolic, V., Tan, J., 2005. The microglial "activation" continuum: from innate to adaptive responses. J Neuroinflammation. 2, 24.

Tsai, H.W., Grant, P.A., Rissman, E.F., 2009. Sex differences in histone modifications in the neonatal mouse brain. Epigenetics. 4 (1), 47-53.

Tsukahara, S., Hojo, R., Kuroda, Y., Fujimaki, H., 2008. Estrogen modulates Bcl-2 family protein expression in the sexually dimorphic nucleus of the preoptic area of postnatal rats. Neurosci Lett. $432(1), 58-63$.

Tsukahara, S., Kakeyama, M., Toyofuku, Y., 2006. Sex differences in the level of Bcl-2 family proteins and caspase-3 activation in the sexually dimorphic nuclei of the preoptic area in postnatal rats. J Neurobiol. 66 (13), 1411-1419.

Valentino, R.J., Van Bockstaele, E., Bangasser, D., 2013. Sex-specific cell signaling: the corticotropin-releasing factor receptor model. Trends Pharmacol Sci. 34 (8), 437-444.

Vamvakopoulos, N.C., Chrousos, G.P., 1993. Evidence of direct estrogenic regulation of human corticotropin-releasing hormone gene expression. Potential implications for the sexual 
dimophism of the stress response and immune/inflammatory reaction. J Clin Invest. 92 (4), 1896-1902.

Veenema, A.H., Bredewold, R., De Vries, G.J., 2013. Sex-specific modulation of juvenile social play by vasopressin. Psychoneuroendocrino. 38 (11), 2554-2561.

Vegeto, E., Benedusi, V., Maggi, A., 2008. Estrogen anti-inflammatory activity in brain: a therapeutic opportunity for menopause and neurodegenerative diseases. Front Neuroendocrinol. 29 (4), 507-519.

Viau, V., Bingham, B., Davis, J., Lee, P., Wong, M., 2005. Gender and puberty interact on the stress-induced activation of parvocellular neurosecretory neurons and corticotropin-releasing hormone messenger ribonucleic acid expression in the rat. Endocrinology. 146 (1), 137-146.

Voskuhl, R.R., Gold, S.M., 2012. Sex-related factors in multiple sclerosis susceptibility and progression. Nat Rev Neurol. 8 (5), 255-263.

Voskuhl, R.R., Pitchekian-Halabi, H., MacKenzie-Graham, A., McFarland, H.F., Raine, C.S., 1996. Gender differences in autoimmune demyelination in the mouse: implications for multiple sclerosis. Ann Neurol. 39 (6), 724-733.

Waddell, J., Bangasser, D.A., Shors, T.J., 2008. The basolateral nucleus of the amygdala is necessary to induce the opposing effects of stressful experience on learning in males and females. J Neurosci. 28 (20), 5290-5294.

Waddington, C.H., 1959. Canalization of development and genetic assimilation of acquired characters. Nature. 183 (4676), 1654-1655.

Wallen, K., 2005. Hormonal influences on sexually differentiated behavior in nonhuman primates. Front Neuroendocrinol. 26 (1), 7-26. 
Wang, S.S., Kamphuis, W., Huitinga, I., Zhou, J.N., Swaab, D.F., 2008. Gene expression analysis in the human hypothalamus in depression by laser microdissection and real-time PCR: the presence of multiple receptor imbalances. Mol Psychiatry. 13 (8), 786-799, 741.

Wang, Z., Bullock, N.A., De Vries, G.J., 1993. Sexual differentiation of vasopressin projections of the bed nucleus of the stria terminals and medial amygdaloid nucleus in rats. Endocrinology. $132(6), 2299-2306$.

Watkins, L.R., Hutchinson, M.R., Ledeboer, A., Wieseler-Frank, J., Milligan, E.D., Maier, S.F., 2007. Norman Cousins Lecture. Glia as the "bad guys": implications for improving clinical pain control and the clinical utility of opioids. Brain Behav Immun. 21 (2), 131-146.

Watson, N.V., Freeman, L.M., Breedlove, S.M., 2001. Neuronal size in the spinal nucleus of the bulbocavernosus: direct modulation by androgen in rats with mosaic androgen insensitivity. $\mathrm{J}$ Neurosci. 21 (3), 1062-1066.

Weickert, C.S., Elashoff, M., Richards, A.B., Sinclair, D., Bahn, S., Paabo, S., Khaitovich, P., Webster, M.J., 2009. Transcriptome analysis of male-female differences in prefrontal cortical development. Mol Psychiatry. 14 (6), 558-561.

Weisz, J., Ward, I.L., 1980. Plasma testosterone and progesterone titers of pregnant rats, their male and female fetuses, and neonatal offspring. Endocrinology. 106 (1), 306-316.

Whitacre, C.C., Reingold, S.C., O'Looney, P.A., 1999. A gender gap in autoimmunity. Science. 283 (5406), 1277-1278.

White, F.A., Keller-Peck, C.R., Knudson, C.M., Korsmeyer, S.J., Snider, W.D., 1998.

Widespread elimination of naturally occurring neuronal death in Bax-deficient mice. J Neurosci. $18(4), 1428-1439$. 
Wijchers, P.J., Yandim, C., Panousopoulou, E., Ahmad, M., Harker, N., Saveliev, A., Burgoyne, P.S., Festenstein, R., 2010. Sexual dimorphism in mammalian autosomal gene regulation is determined not only by Sry but by sex chromosome complement as well. Dev Cell. 19 (3), 477484.

Wright, C.L., Burks, S.R., McCarthy, M.M., 2008. Identification of prostaglandin E2 receptors mediating perinatal masculinization of adult sex behavior and neuroanatomical correlates. Dev Neurobiol. 68 (12), 1406-1419.

Wright, C.L., McCarthy, M.M., 2009. Prostaglandin E2-induced masculinization of brain and behavior requires protein kinase A, AMPA/kainate, and metabotropic glutamate receptor signaling. J Neurosci. 29 (42), 13274-13282.

Wu, M.V., Manoli, D.S., Fraser, E.J., Coats, J.K., Tollkuhn, J., Honda, S., Harada, N., Shah, N.M., 2009. Estrogen masculinizes neural pathways and sex-specific behaviors. Cell. 139 (1), 61-72.

Xu, J., Deng, X., Disteche, C.M., 2008. Sex-specific expression of the X-linked histone demethylase gene Jarid1c in brain. PLoS One. 3 (7), e2553.

Xu, X., Coats, J.K., Yang, C.F., Wang, A., Ahmed, O.M., Alvarado, M., Izumi, T., Shah, N.M., 2012. Modular genetic control of sexually dimorphic behaviors. Cell. 148 (3), 596-607.

Yang, F., Deng, X., Ma, W., Berletch, J.B., Rabaia, N., Wei, G., Moore, J.M., Filippova, G.N., Xu, J., Liu, Y., Noble, W.S., Shendure, J., Disteche, C.M., 2015. The IncRNA Firre anchors the inactive $\mathrm{X}$ chromosome to the nucleolus by binding CTCF and maintains H3K27me3 methylation. Genome Biol. 16, 52. 
Yang, X., Schadt, E.E., Wang, S., Wang, H., Arnold, A.P., Ingram-Drake, L., Drake, T.A., Lusis, A.J., 2006. Tissue-specific expression and regulation of sexually dimorphic genes in mice. Genome Res. 16 (8), 995-1004.

Yurkovetskiy, L., Burrows, M., Khan, A.A., Graham, L., Volchkov, P., Becker, L., Antonopoulos, D., Umesaki, Y., Chervonsky, A.V., 2013. Gender bias in autoimmunity is influenced by microbiota. Immunity. 39 (2), 400-412.

Zhang, J.M., Konkle, A.T., Zup, S.L., McCarthy, M.M., 2008. Impact of sex and hormones on new cells in the developing rat hippocampus: a novel source of sex dimorphism? Eur $\mathrm{J}$ Neurosci. 27 (4), 791-800.

Zuloaga, D.G., Puts, D.A., Jordan, C.L., Breedlove, S.M., 2008. The role of androgen receptors in the masculinization of brain and behavior: what we've learned from the testicular feminization mutation. Horm Behav. 53 (5), 613-626.

Zup, S.L., Carrier, H., Waters, E.M., Tabor, A., Bengston, L., Rosen, G.J., Simerly, R.B., Forger, N.G., 2003. Overexpression of bcl-2 reduces sex differences in neuron number in the brain and spinal cord. J Neurosci. 23 (6), 2357-2362. 


\section{Figure Legends}

Figure 1. Female sexual behavior is eliminated and male sexual behavior is increased in female alpha-fetoprotein (Afp) knockout mice. (A,B) Lordosis quotients in three consecutive tests of $A f p^{-}$

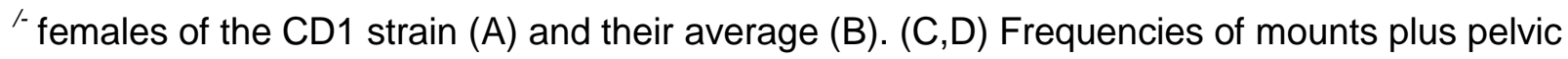
thrusting in three consecutive tests (C) and their average (D). ${ }^{*} P<0.05$ compared to wild-type mice; $\# P<0.05$ compared to $A f p^{+/}$. The number of animals per group is indicated at the base of the bars in (B) and (D). Reproduced from Bakker et al. (2006) with permission of Nature Publishing Group.

Figure 2. Cell number in the principal nucleus of the bed nucleus of the stria terminalis (BNSTp) of wild-type $(\mathrm{Bax}+/+)$ and Bax knockout (Bax -/-) mice. (A) Photomicrograph of the mouse BNSTp (arrows) in a thionin stained tissue section. (B) Cell number in the BNSTp is greater in wild-type males than in females. Deletion of the Bax gene increases cell number in both sexes but more so in females than in males. As a result, the sex difference is eliminated in Bax -/mice. The number of animals per group is indicated at the base of each bar. n.s., not significant. Reproduced from Forger et al. (2004) with permission of the National Academy of Sciences U.S.A.

Figure 3. Quantification of spinal nucleus of the bulbocavernosus (SNB) motoneuron number in adult wild-type (WT) and androgen receptor mutant (AR-) male rats with and without a transgene (tg) that restricts expression of functional androgen receptors only to skeletal muscle cells. SNB motoneurons were more numerous in WT males than AR- males, and there was no effect of the transgene. Different letters over the bars indicate significant differences between groups. Data provided by D. A. Monks and adapted for this review. 
Figure 4. Total cell number and the number of phenotypically identified subsets of cells in the anteroventral periventricular nucleus (AVPV) of wild-type $(\mathrm{Bax}+/+)$ and Bax knockout (Bax -/-) mice. (A) Total cell number determined by stereological cell counts in a thionin stain; (B) dopaminergic cell number identified by tyrosine hydroxylase immunoreactivity ( $\mathrm{TH}$-ir); (C) the number of cells expressing kisspeptin (Kiss1) mRNA as determined by in situ hybridization. Cell number is greater in wild-type females than in wild-type males in each case. Bax deletion eliminates the sex difference in total cell number, but does not affect $\mathrm{TH}$-ir or kisspeptin cell number. (D) Photomicrographs of sections through the AVPV processed for detection of kisspeptin mRNA by in situ hybridization. n.s., not significant. (A, B) reproduced from Forger et al. (2004), with permission of the National Academy of Sciences U.S.A.; (C, D) reproduced from Semaan et al. (2010) with permission of the Endocrine Society.

Figure 5. Mechanisms of estradiol-induced morphological changes in the rat hypothalamus. (A) In the arcuate nucleus (ARC), estradiol increases the expression of glutamic acid decarboxylase (GAD), an enzyme required for GABA production, and increases GABA release. This causes increased astrocyte complexity. (B) In the preoptic area (POA), estradiol increases expression of cyclooxygenase-2 (Cox-2), which increases production of prostaglandin $E_{2}\left(\mathrm{PGE}_{2}\right)$ in both neurons and microglia, increasing spine density on postsynaptic neurons. Estradiol may act via microglia, because inhibiting microglial activation prevents effects of estradiol on spine density. (C) In the ventromedial nucleus of the hypothalamus $(\mathrm{VMH})$, estradiol increases glutamate release through an unknown mechanism, which causes increases in primary dendrite length of postsynaptic VMH neurons. [Original artwork by JAS, based on the work of Mong et al. (2002), Lenz et al. (2013) and Schwarz et al. (2008).] 
Figure 6. Effects of neonatal treatment with testosterone on the DNA methylome of female mice. (A) Number of genes where methylation was significantly different between control females and females treated with testosterone on the day of birth. The striatum and bed nucleus of the stria terminalis/ preoptic area of the hypothalamus (BNST/POA) were examined at postnatal day (PN) 4 and PN60. DNA methylation of fewer than 100 genes were affected at PN4 and many more were affected at PN60 in both brain regions. (B) Percentage of genes that exhibit testosterone-dependent hypo- or hyper-methylation at each age in each brain region. At both ages and in both brain regions, the large majority of genes with a difference in methylation were more methylated (blue) in females that received testosterone on PN0. Adapted from Ghahramani et al. (2014) with permission from BioMed Central Ltd.

Figure 7. Sex differences and effects of simulated maternal grooming on methylation of the estrogen receptor alpha (ERa) promoter in the preoptic area of the hypothalamus (POA). In the neonatal rat POA, ERa promoter methylation (red circles with letter $\mathrm{M}$ ) is greater in males than in females, and corresponding sex differences in ERa mRNA and protein are seen, with lower levels in males. Simulated maternal grooming (SMG) of females masculinizes the patterns of ERa promoter methylation and ERa expression. [Original artwork by ACR, based on the work of Kurian et al. (2010)].

Figure 8. Sex differences in corticotropin-releasing factor receptor 1 (CRF1) signaling cascades. In female rats, there is a low level of association of CRF1 with $\beta$-arrestin 2 ( $\beta$-arr) which biases signaling through $G$ protein $(G)$-dependent pathways. In contrast, the CRF1 receptor associates with $\beta$-arr in males, which results in a relative bias towards $\mathrm{G}$-independent pathways. Because distinct signaling pathways are activated, different cellular responses are likely to be elicited, which in turn may lead to sex-specific physiological and behavioral outcomes in health and disease. The specific pathologies shown [depression, post-traumatic 
stress disorder (PTSD), irritable bowel syndrome, substance abuse] have not yet been directly linked to the disparate molecular CRF1 signaling pathways in males and females, but are examples of stress-related pathologies that are more prevalent in one sex than the other. Adapted from Valentino et al. (2013) with permission of Elsevier Ltd.

Figure 9. The "SexOrganome" is defined as the sum total of all peripheral influences on sex differences in the central nervous system (De Vries and Forger, 2015), some of which are shown here. The central nervous system is embedded in a sexually differentiated body. Solid arrows indicate a sex influence from one organ on another. Dashed arrows indicate an influence inferred from circumstantial evidence, but not yet demonstrated (for further discussion see De Vries and Forger, 2015). Black arrows indicate neural communication; red arrows indicate humoral communication. " $X X X Y$ " indicates organs in which sex chromosome complement has a demonstrated effect; in most cases, it is not known whether the effect is mediated within that organ or indirectly via effects on other organs. The body, in turn, is embedded in an environment that affects the individual in a manner that varies by sex. The small colored circles in the upper right are the many species of microorganisms living commensally in our gut or on our skin (microbiota). On the left, vision, olfaction, touch, and taste may all be processed differently in males and females. Reproduced from de Vries and Forger (2015) with permission from BioMed Central Ltd. 
A

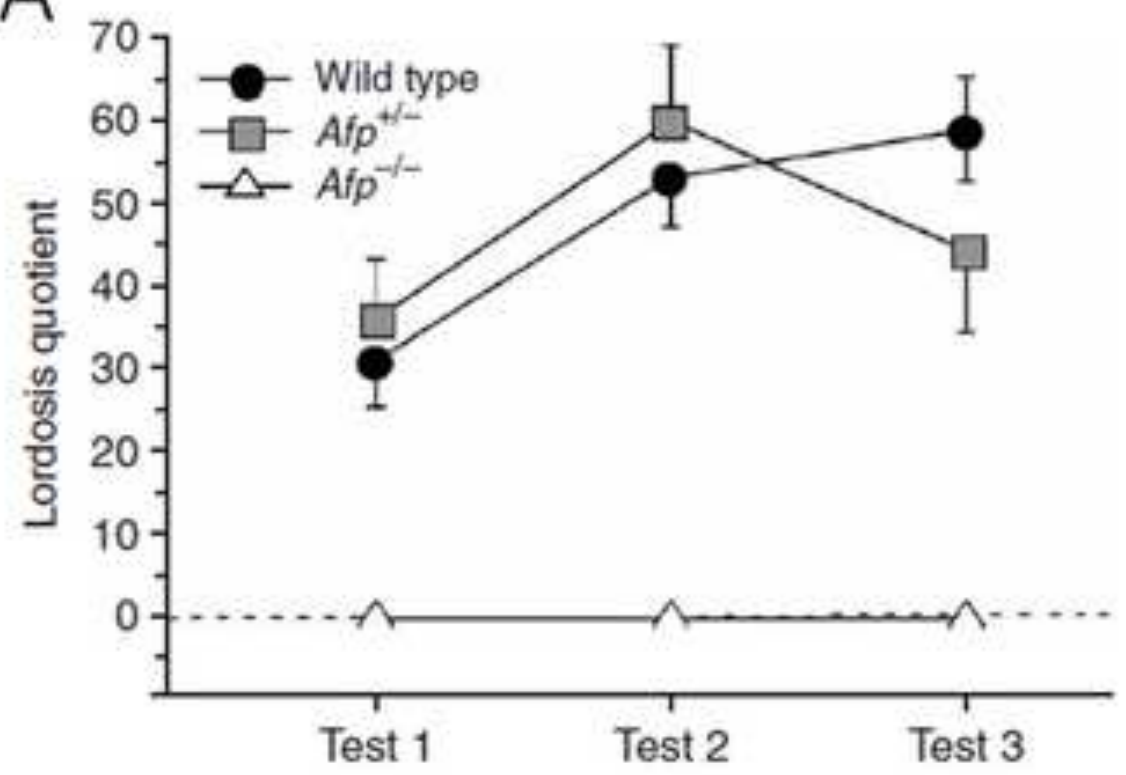

$C$

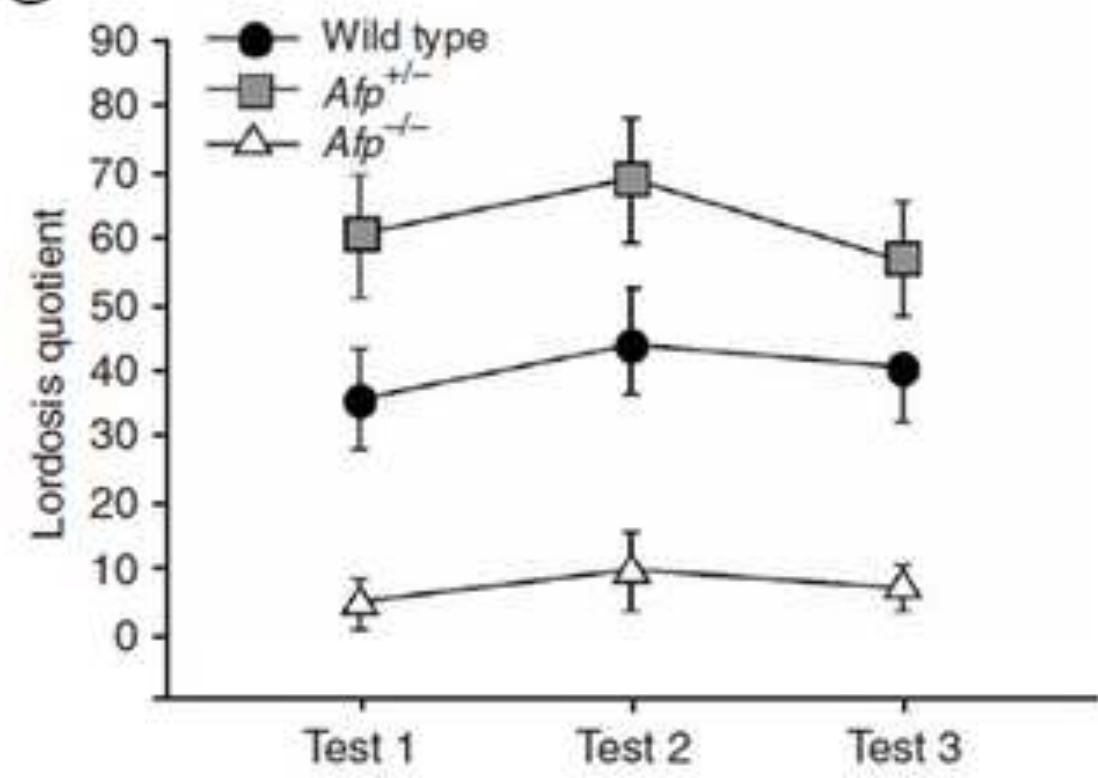

B

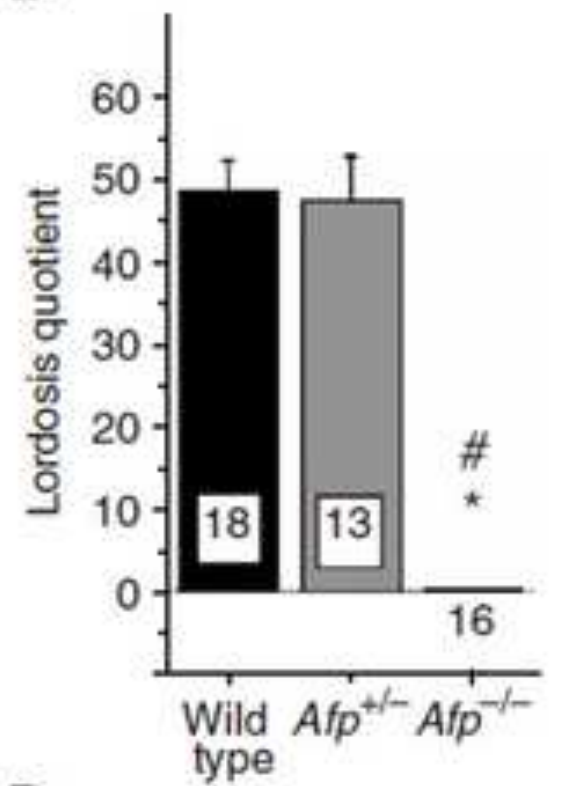

D

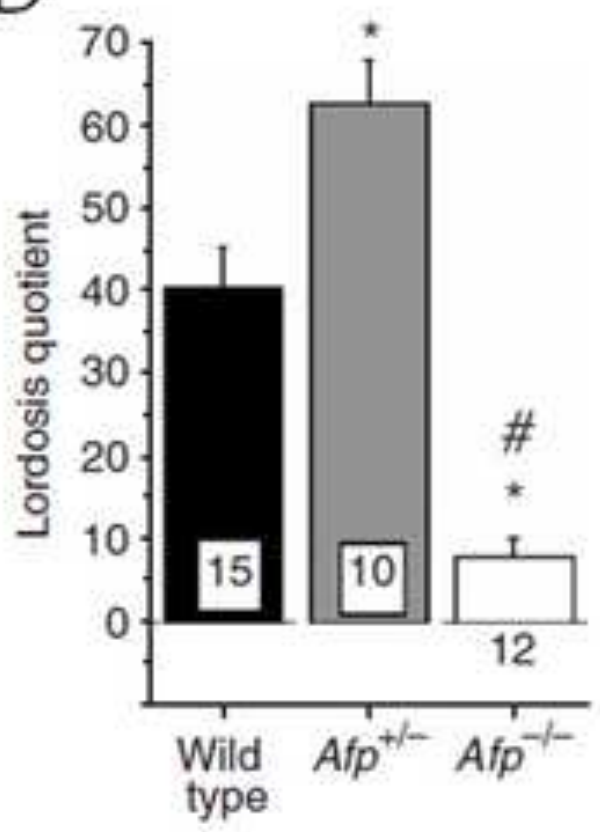



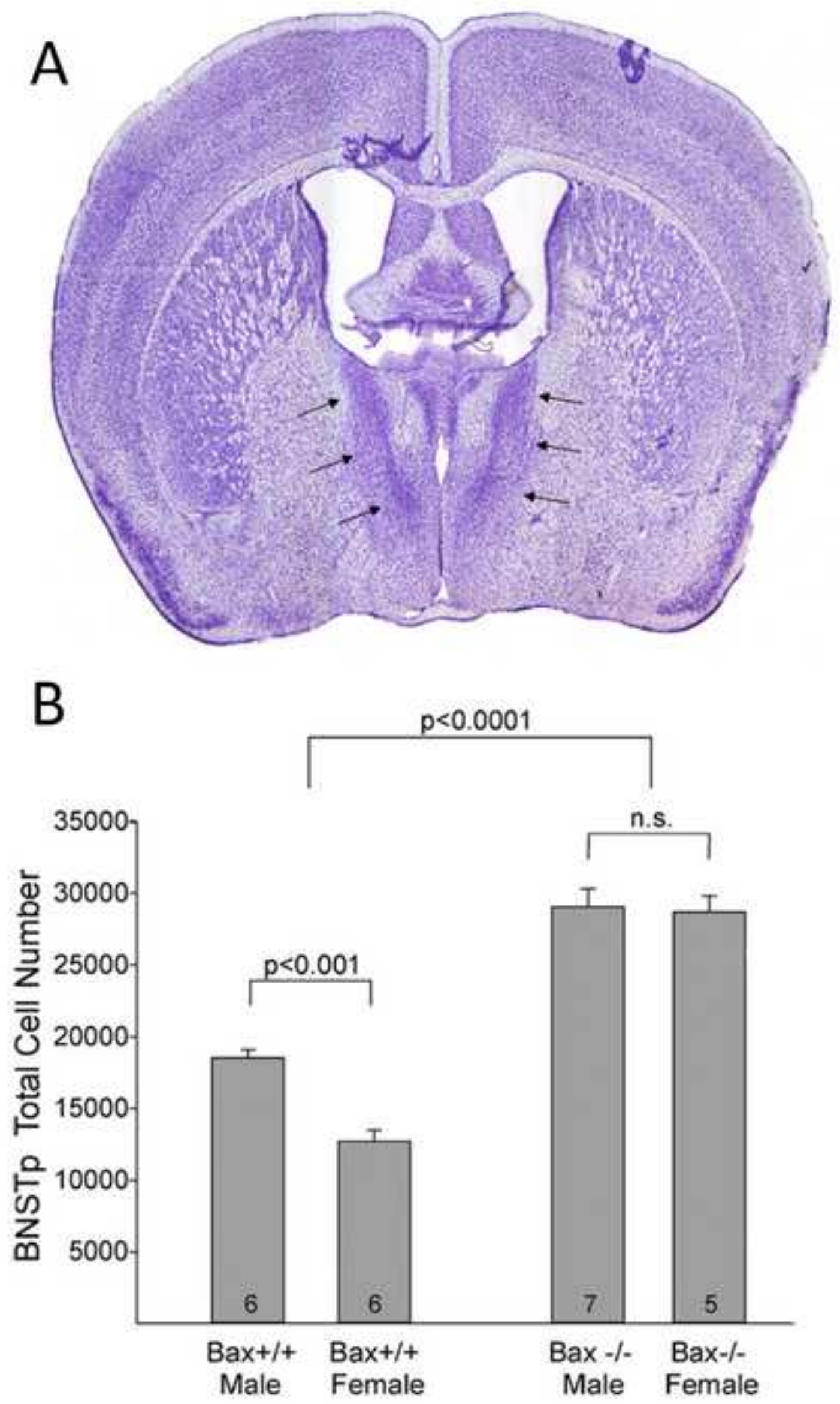

Sex-by-genotype interaction: $p<0.015$ 


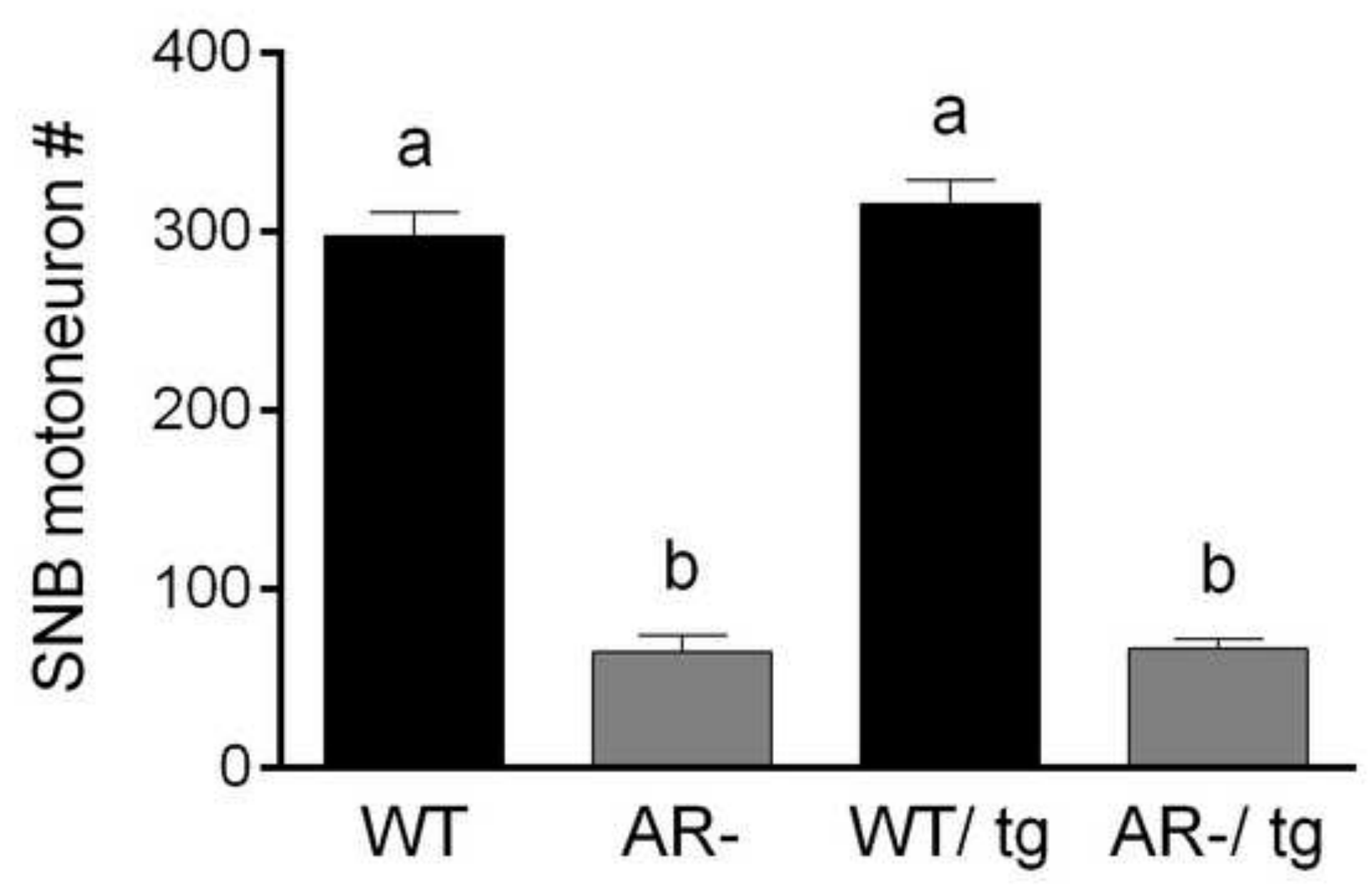


A

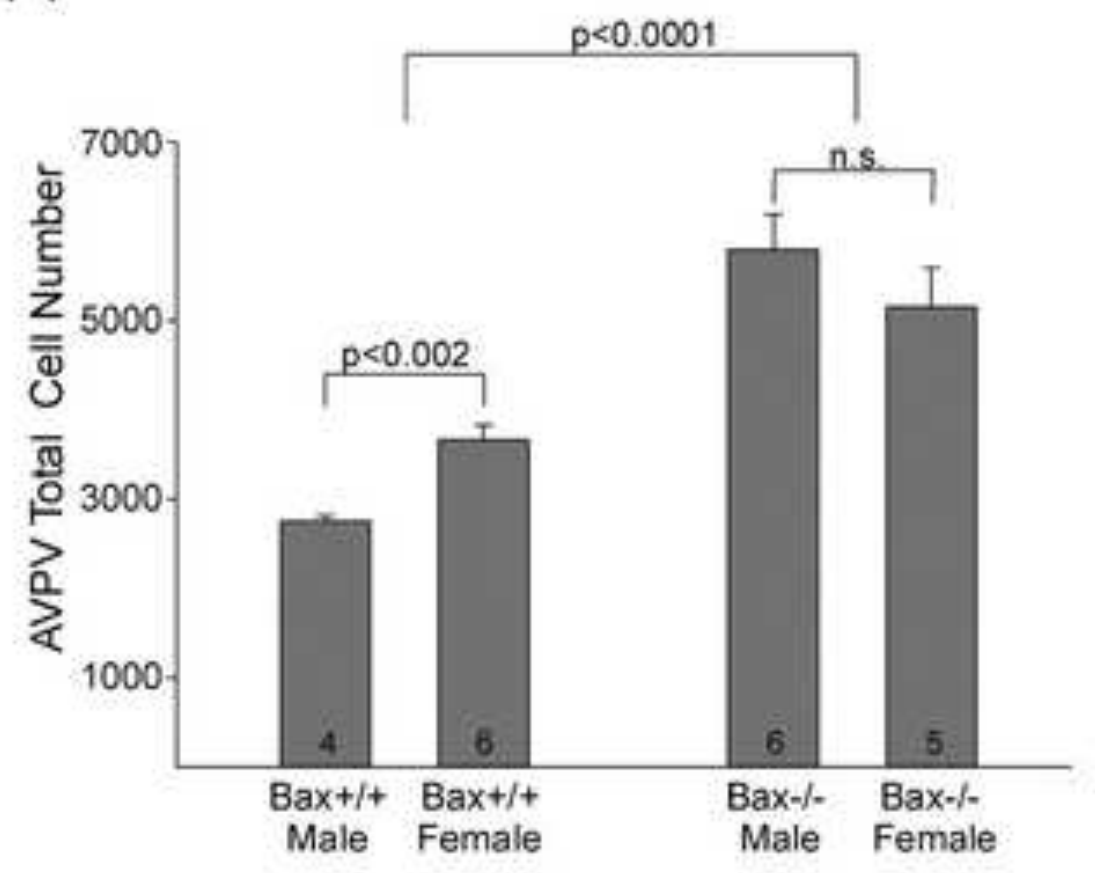

Sex-by-genotype interaction: $p<.03$

C

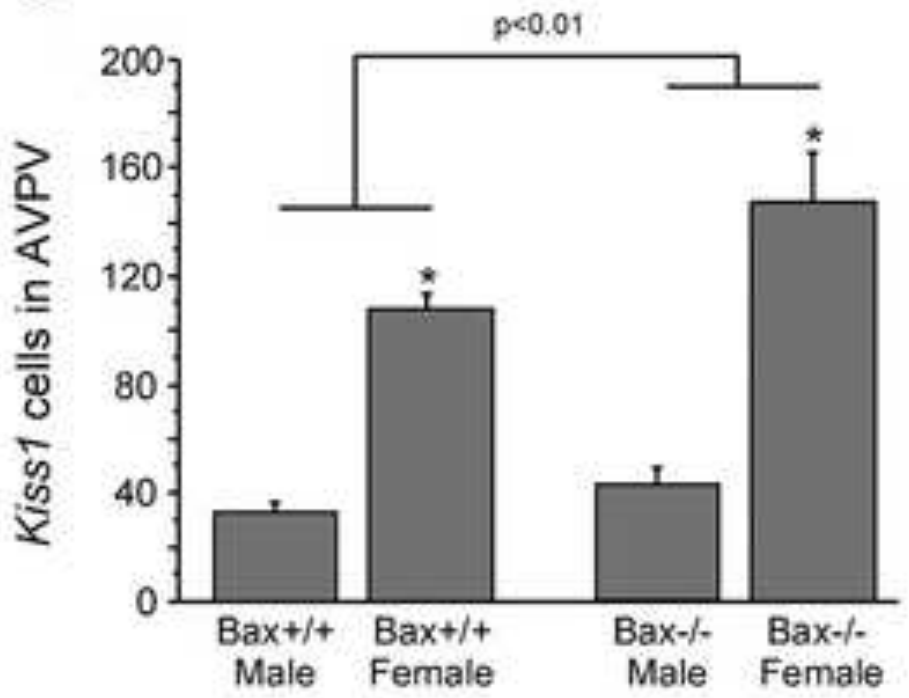

B

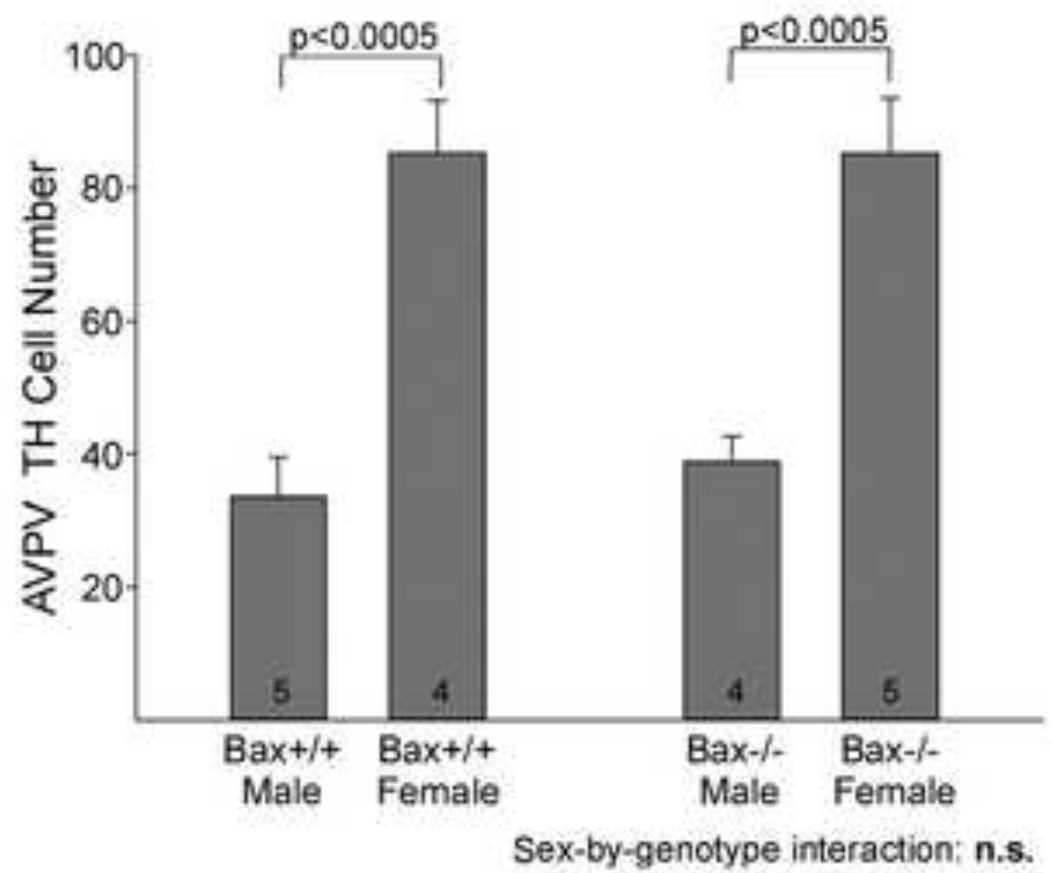

D
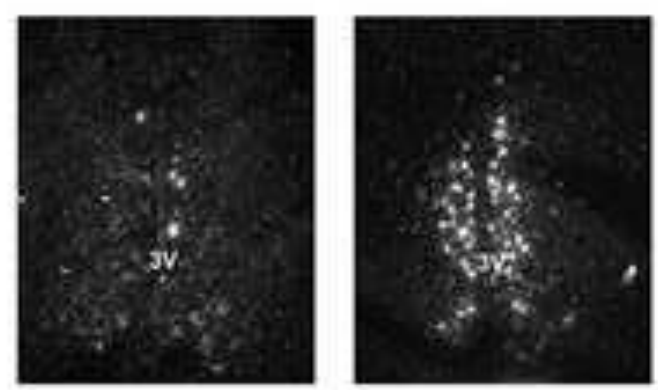

Bax+l+ Male
Kiss1 cells in AVPV

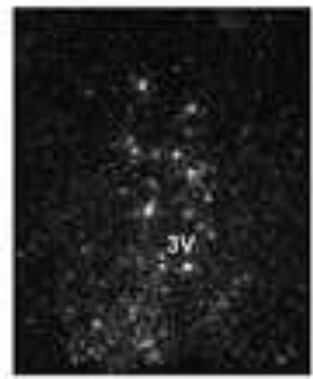

Bax-/-

Baxt/4

Female

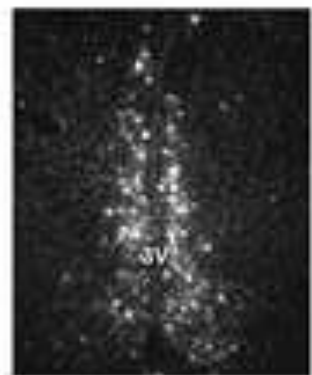

Bax $=\%$

Female 


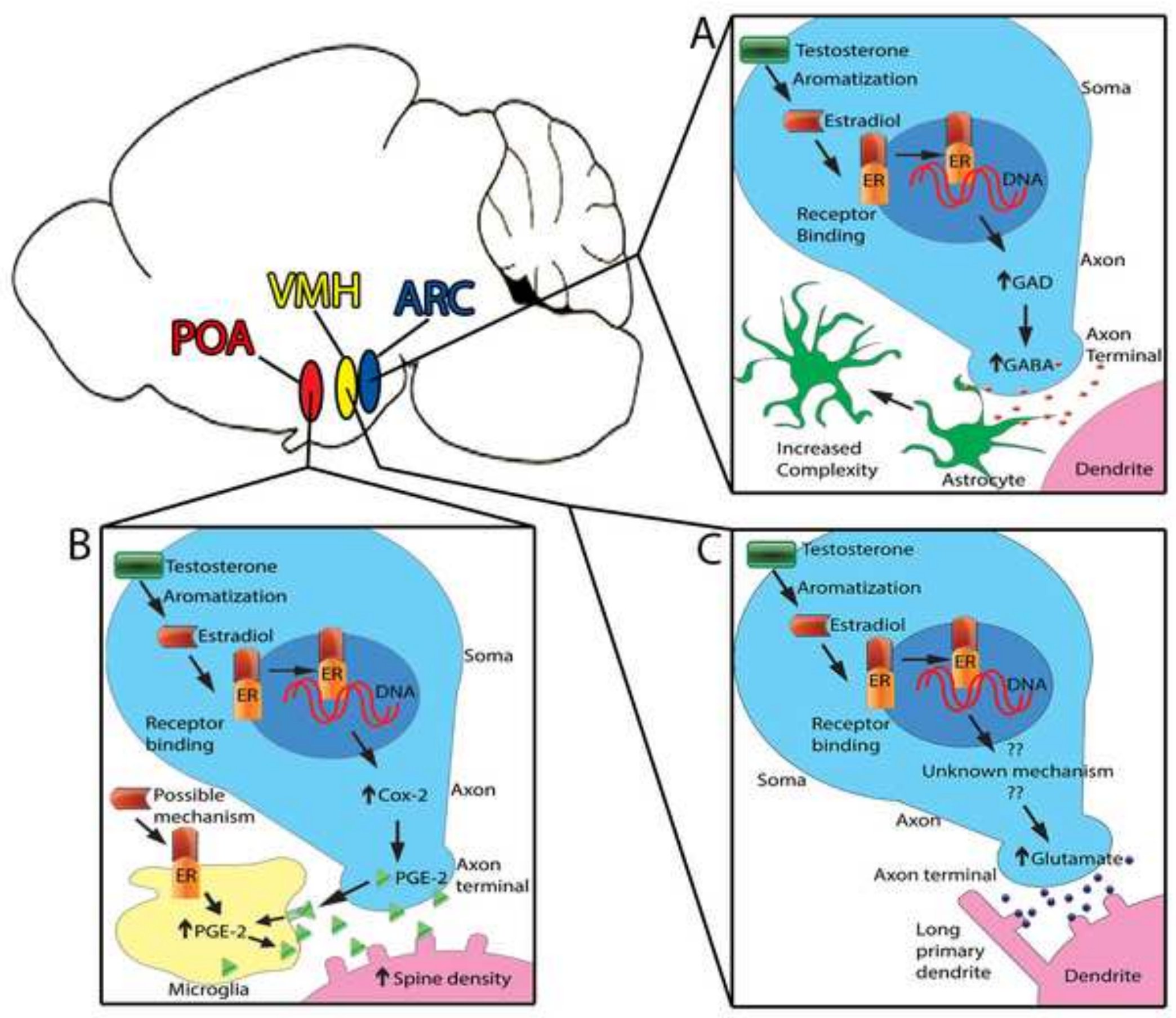


A

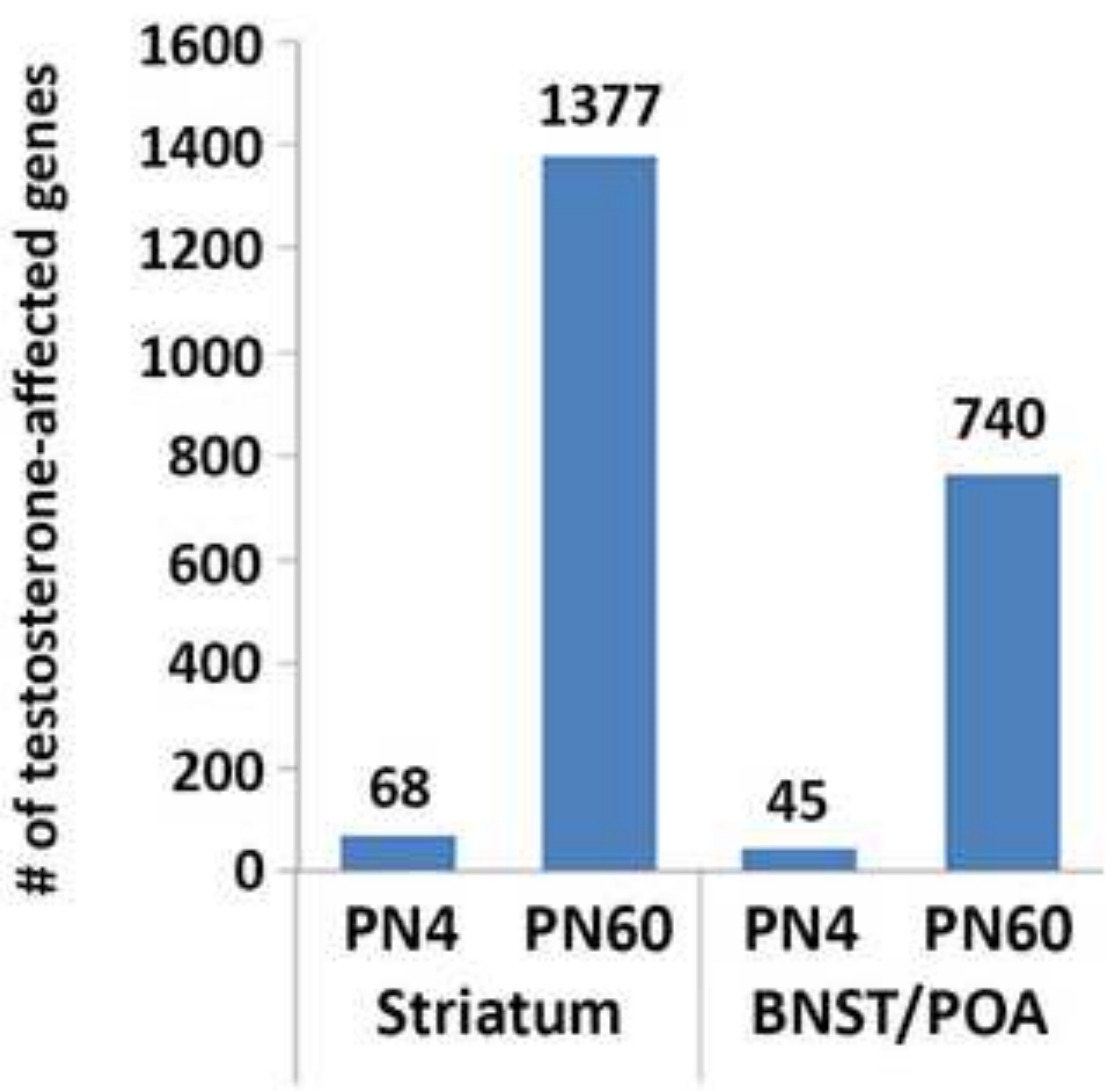

B

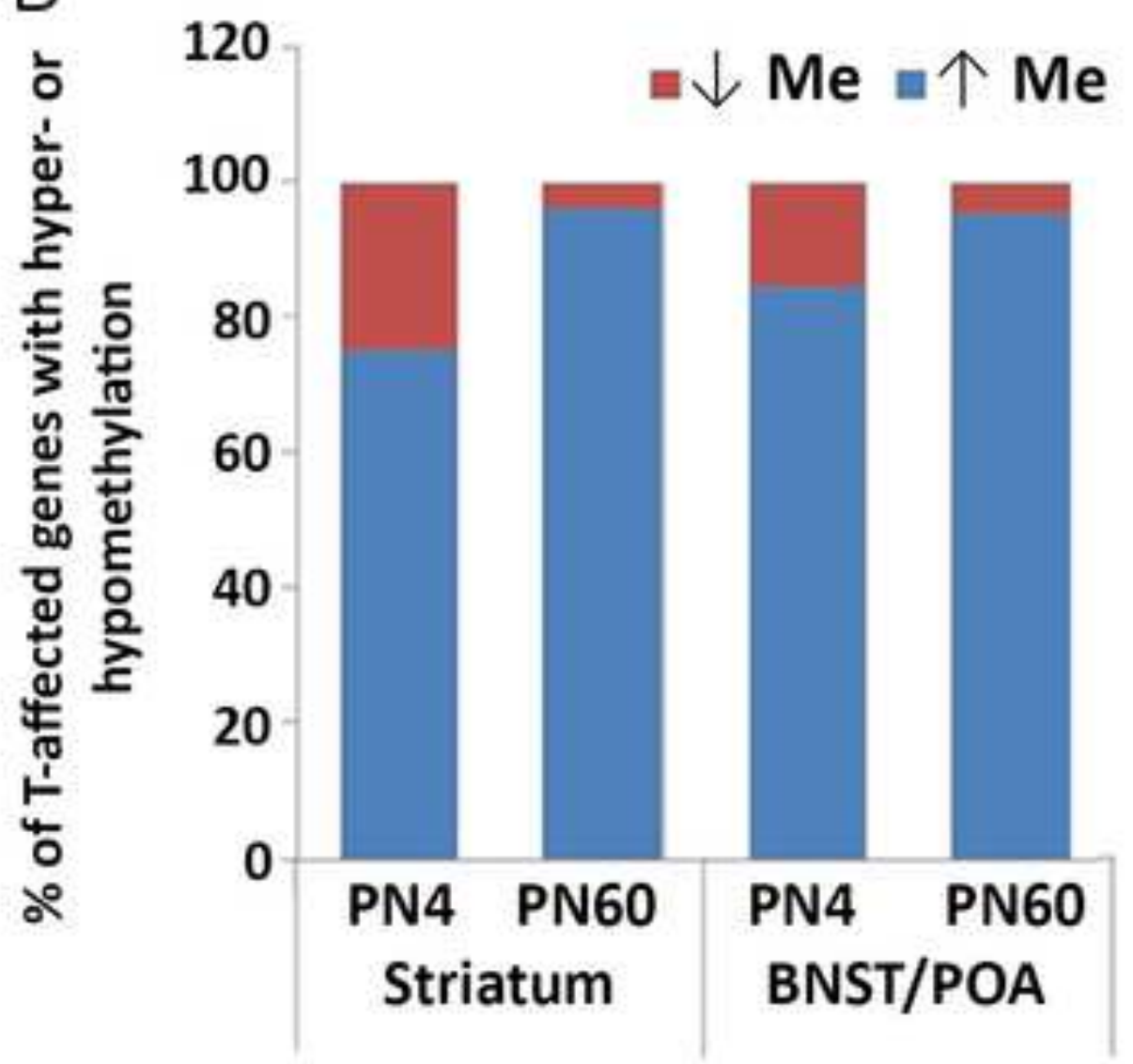



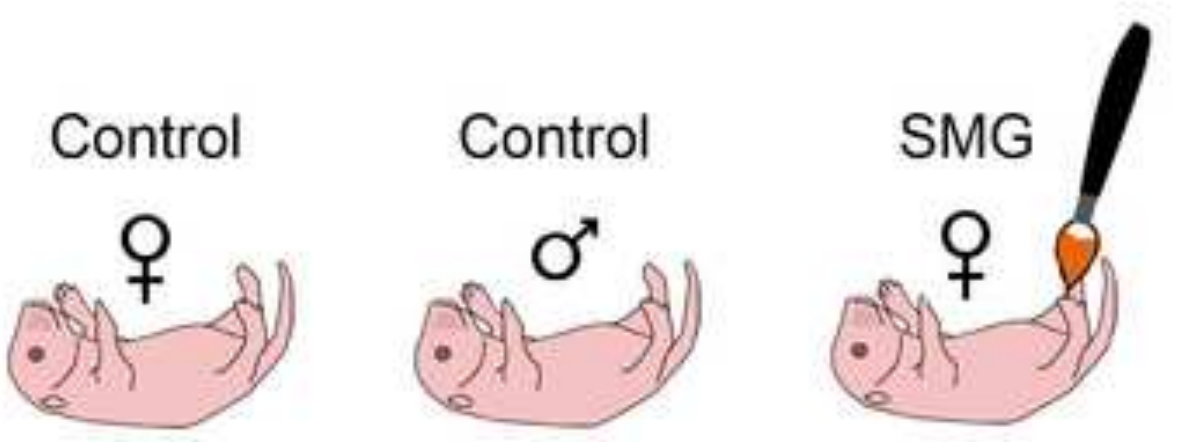

\section{Effects on}
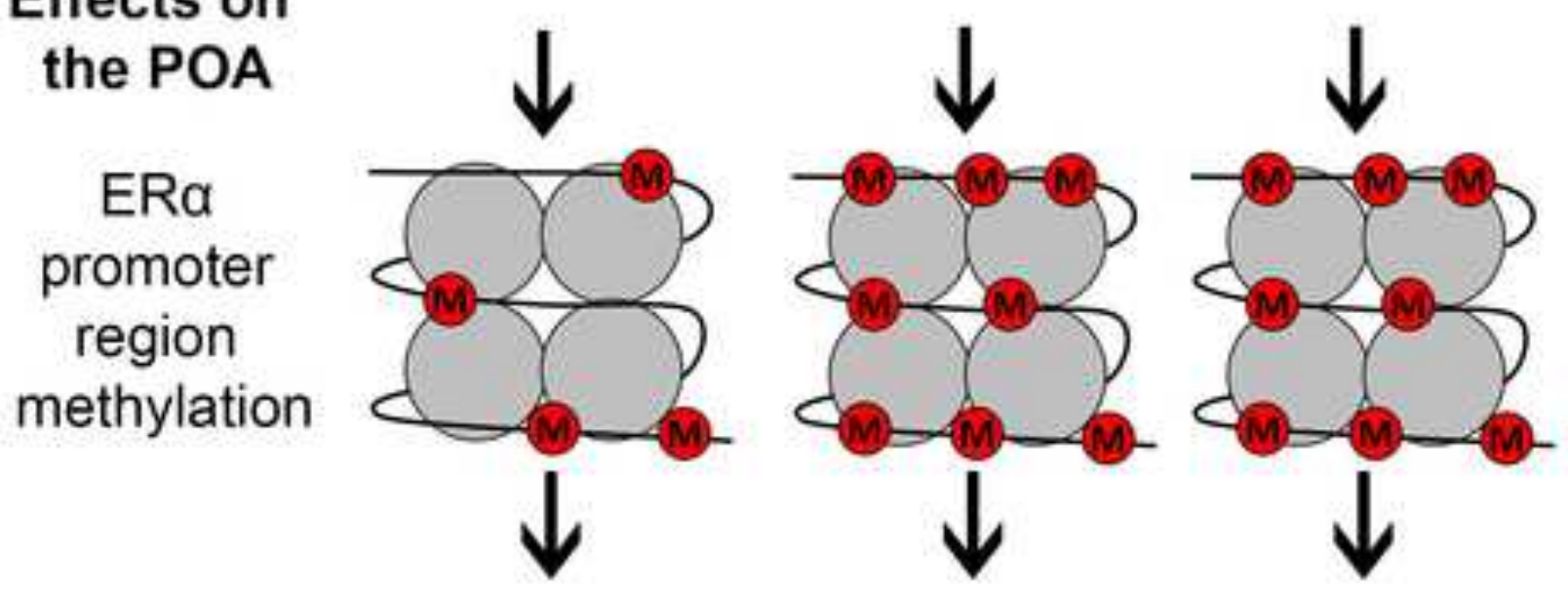

ER $\alpha$ mRNA
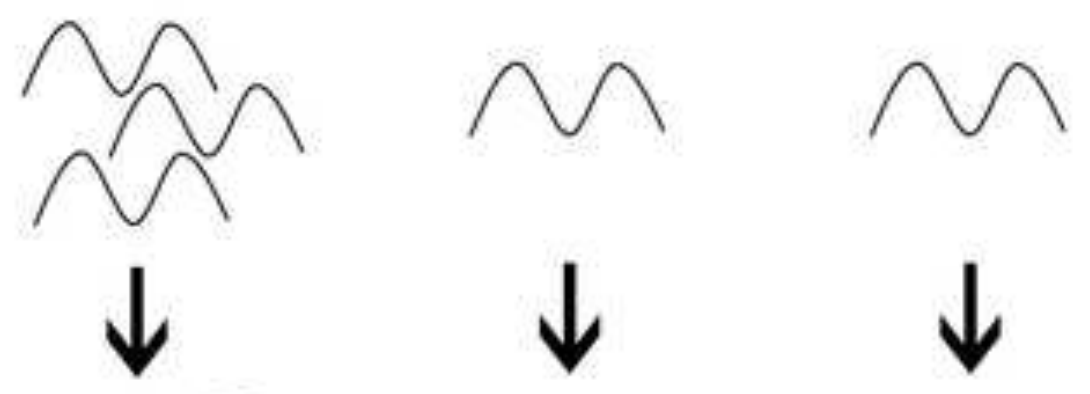

ERa protein
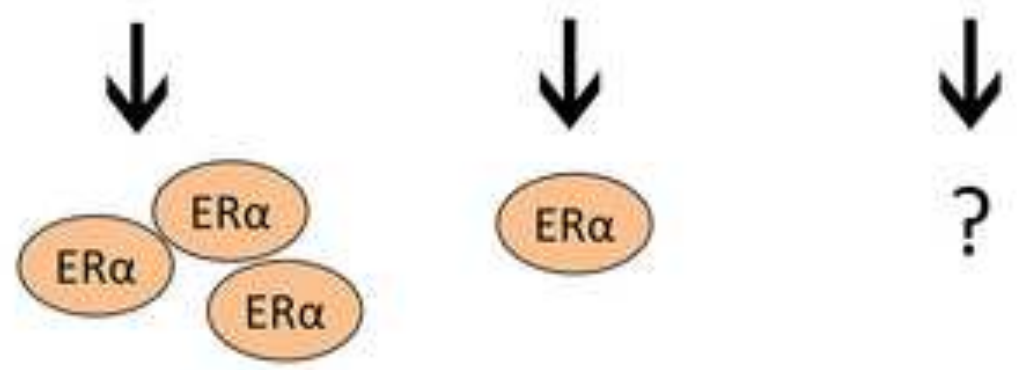

? 


\section{Sex biased CRF1 signaling}

Female: $\mathrm{G}$ protein bias
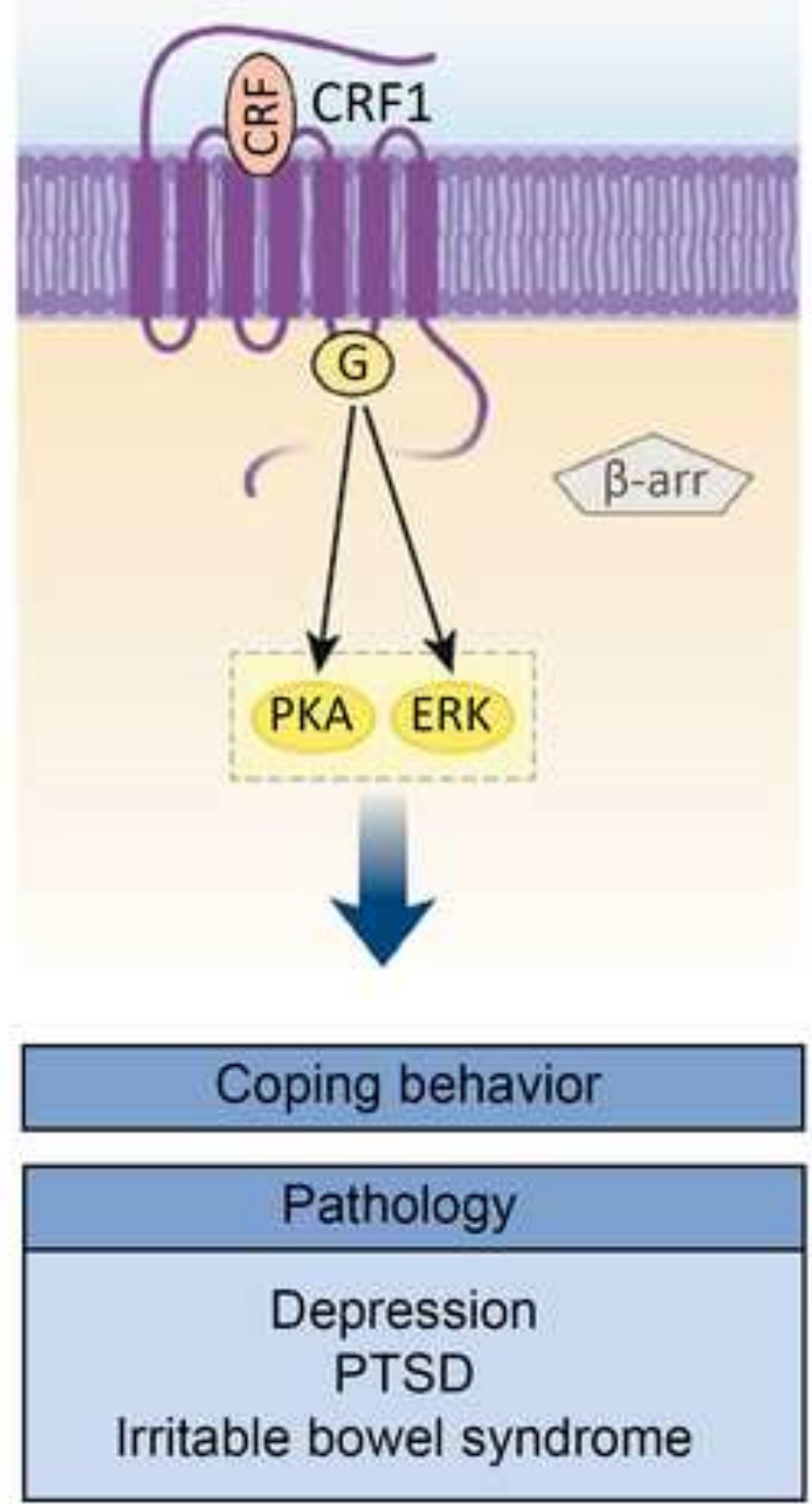

Male: $\beta$-arrestin 2 bias
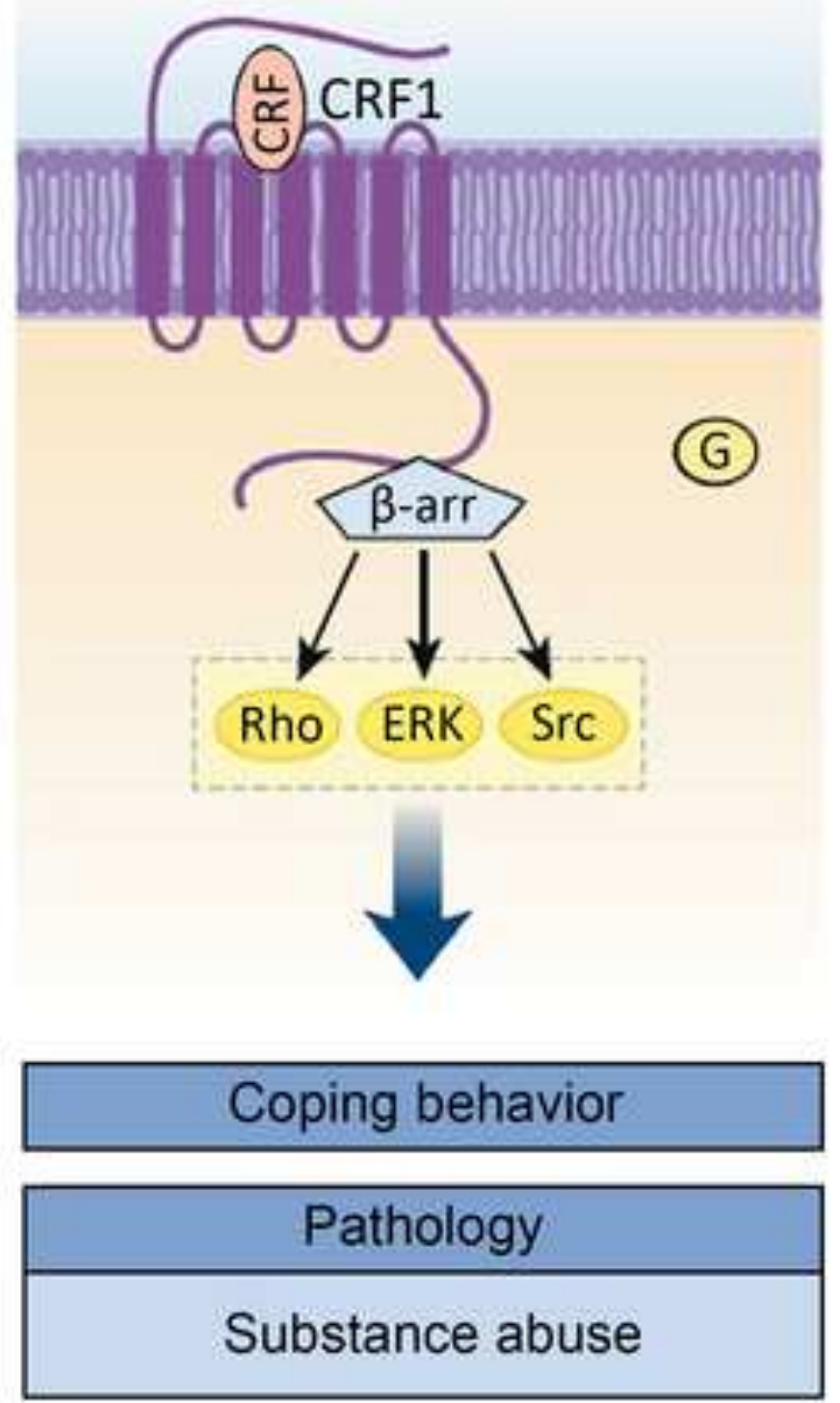


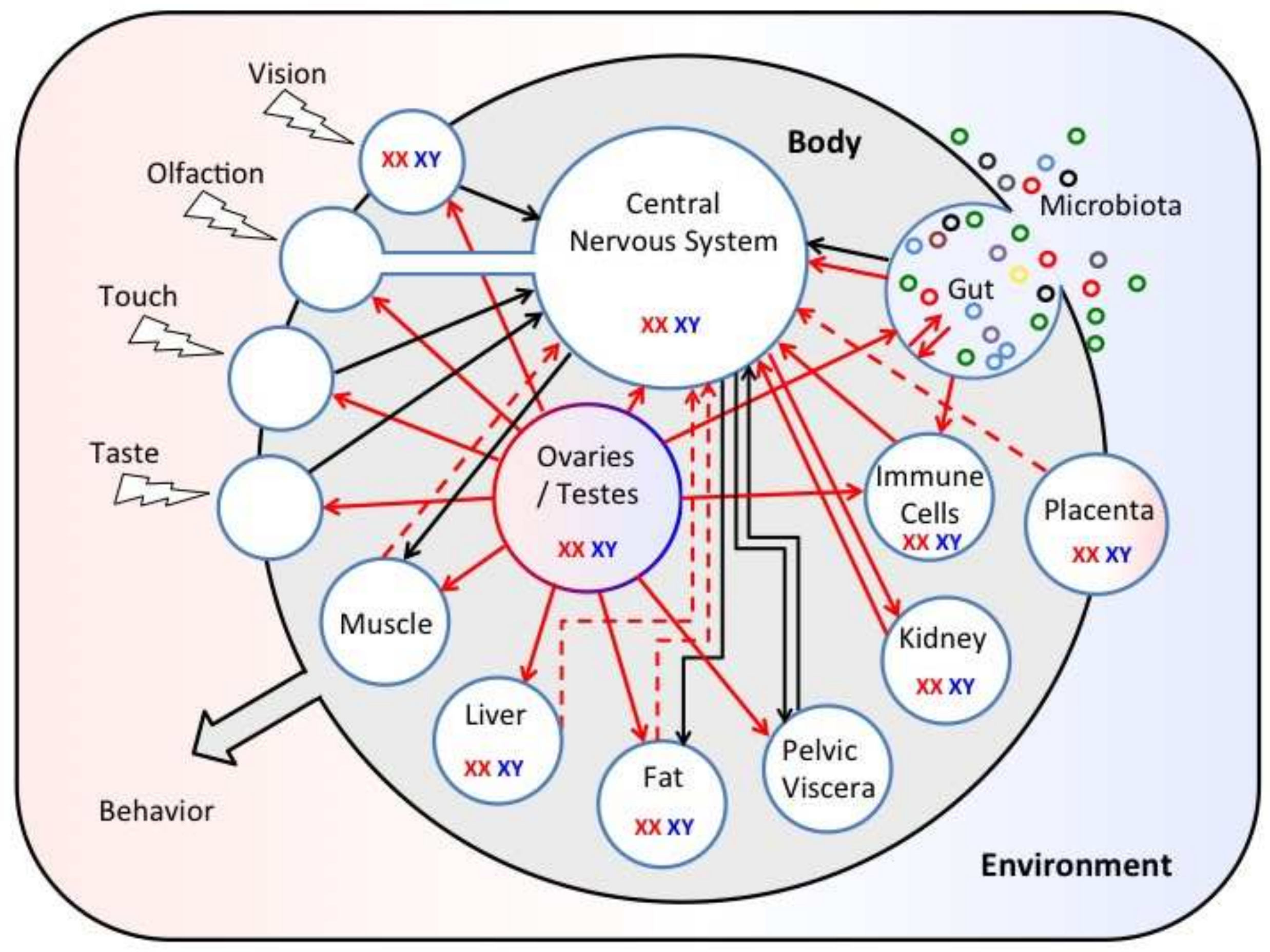

